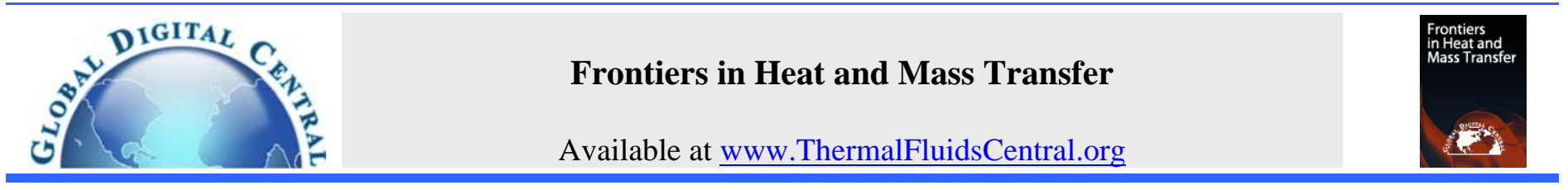

\title{
3D NUMERICAL ANALYSIS ON FLOW CONFIGURATIONS AND HEAT TRANSFER CHARACTERISTICS FOR FIN-AND-OVAL-TUBE HEAT EXCHANGER WITH V-DOWNSTREAM DELTA WINGLET VORTEX GENERATORS
}

\author{
Amnart Boonloi ${ }^{\mathrm{a}}$ and Withada Jedasadaratanachai ${ }^{\mathrm{b}, *}$ \\ ${ }^{a}$ Department of Mechanical Engineering Technology, College of Industrial Technology, King Mongkut's University of Technology North Bangkok, \\ Bangkok 10800, Thailand \\ ${ }^{b}$ Department of Mechanical Engineering, Faculty of Engineering, King Mongkut's Institute of Technology Ladkrabang, Bangkok 10520, Thailand
}

\begin{abstract}
3D numerical investigations for heat transfer characteristics and flow configurations in a fin-and-oval-tube heat exchanger with V-tip pointing downstream delta winglet pairs $(D D W P)$ are examined. The $D D W P$ s are placed on the fin surface with pointing downstream and the oval tube row number is set at three in a staggered arrangement. The flow attack angles $\left(\theta=15^{\circ}, 30^{\circ}, 45^{\circ}\right.$ and $\left.60^{\circ}\right)$ and the distance from V-tip to the oval tube center in transverse axis $(a=3.77,4.77$ and $5.77 \mathrm{~mm})$ are investigated for Reynolds number based on hydraulic diameter, $R e=500-2500$. The numerical results are compared with the previous experimental results and the validations of the grid system on both heat transfer and friction factor are also reported. As the results, it is found that the use of the $D D W P$ performs higher heat transfer rate and the friction factor than the smooth fin with no $D D W P$ for all cases. The vortex flows and the impinging jet of the flows over the oval-tube walls lead to the increase in heat transfer rate, but also increase in pressure loss. The augmentations are maximum around 1.59 and 4.4 times higher than the smooth fin for heat transfer and friction factor, respectively. In addition, the optimum thermal enhancement factor, $T E F$, is around 1.09 at $\operatorname{Re}=2500, a=5.77 \mathrm{~mm}$ and $\theta=15^{\circ}$.
\end{abstract}

Keywords: Compact heat exchanger, Delta winglet, Fin-and-oval-tube, Laminar flow, Thermal enhancement factor

\section{INTRODUCTION}

Compact heat exchangers as a fin-and-tube heat exchanger are widely used in many industrials and equipment; electronic equipment, air conditioning, automobiles, refrigeration, radiator, chemical industry, etc. Several investigators had been attempted to enhance thermal performance of the compact heat exchanger by using turbulators or vortex generators. Many types of the vortex generator; winglet, wing, baffle, rib, groove, etc., had been installed in the heat exchanger for augmenting heat transfer and their performance. The use of the vortex generators leads to increase in vortex strength or turbulence intensity, secondary flows and disrupting the boundary layer. The vortex generator can be divided into two types; longitudinal vortex generators $(L V G)$ and transverse vortex generator $(T V G)$ considered from the axes of vortices which created from the vortex generators.

Thermal performance enhancement in fin-and-tube heat exchangers with various types of vortex generators has been studied. The experimental and numerical investigations on the vortices in internal flow were reported by Fiebig, 1995. He found that the longitudinal vortices perform better heat transfer augmentation than transverse vortices with similar pressure loss values. He also summarized that the winglets give the nearly value of heat transfer rate for less pressure loss in comparison with the wings. Zhu et al., 1995, numerical studied combined vortex generators; longitudinal vortex generators and rib turbulators, in a rectangular channel on heat transfer for turbulent flow regime. They reported that the combined vortex generators can increase the average Nusselt number around $450 \%$. The literature reviews for heat transfer augmentation with longitudinal vortices were explained by Jacobi and Shah, 1995. Biswas et al., 1996, investigated on both numerical and experimental for the influences of longitudinal vortices in a channel on heat transfer characteristics and flow configurations. They concluded that the flow configurations can be divided into three parts; main vortex flow, corner vortex flow and induced vortex flow. They also found that the appearance of the complex flow provided the increase in heat transfer and thermal performance in the test section. Lee et al., 1999, numerical investigated a test channel with longitudinal vortices for turbulent regimes. They reported that the disturbance of the boundary layer nears the channel wall regime results in the heat transfer augmentation. The influences of the vortex generator configurations on heat transfer and fluid flow were studied by Liou et al. (2000). They found that the important factors for heat transfer enhancement are the direction and intensity of the secondary flow. Torii et al. (2002) experimentally studied on the effect of the delta winglet vortex generators in a fin-and-tube heat exchanger with in-line or staggered tube banks on heat transfer and pressure loss. They showed that the staggered tube banks case provides the heat transfer augmentation around $10-30 \%$ and the pressure loss is reduced by $34-55 \%$ for $R e=$ $350-2100$.

*Corresponding author.Email:kjwithad@kmitl.ac.th 
Gentry and Jacobi (2002) studied the influences of the delta-winggenerated tip vortices in a flat-plate and developing channel flows. The enhancements were around 55\% and $100 \%$ for heat transfer and friction factor, respectively, which described by Gentry and Jacobi, 2002. Leu et al. (2004) investigated a plate-fin and tube heat exchanger with inclined block shape vortex generators placed behind the tubes on heat transfer and flow configurations by using numerical and experimental methods. Sommers and Jacobi, 2005, experimental investigated the use of vortex generators on the air-side of the evaporator. They concluded that the use of the vortex generators can reduce the thermal resistance around $35-42 \%$ of $R e=500-1300$. Pesteei et al., 2005 found that the optimum heat transfer enhancement for winglet pairs is appeared when placed at the downstream regime. The numerical investigation on the winglet pair with zero thickness on heat transfer was described by Hiravennavar et al., 2007. They found that the heat transfer enhancement is around $33 \%$ and $67 \%$ for single winglet and winglet pair, respectively.

The investigations on heat transfer augmentations in a finned oval tube with inline longitudinal vortex generators (Chen et al., 1998) and with staggered longitudinal vortex generators (Chen et al., 2000) were reported. Tiwari et al., 2003, numerical investigated heat transfer and thermal performance in a channel with built-in oval tube and delta winglet vortex generators for laminar flow. They exposed that the use of the winglet pairs can significantly increase in heat transfer rate and thermal performance in the heat exchanger. O'Brien et al., 2004, studied an elliptical tube with one or two delta-winglet pairs in a rectangular channel on thermal performance. They reported that the presence of the single winglet pair to the oval-tube geometry leads to the increase in heat transfer around 38\% in comparison with no winglet case. However, the use of the delta-winglet pairs not only increase in heat transfer but also increase in friction factor which also concluded by O'Brien et al. (2004). Chu et al. (2009) studied a fin-and-oval-tube heat exchanger with longitudinal vortex generators $(L V G \mathrm{~s})$ on heat transfer configuration, thermal performance and flow behavior. They found that the enhancements are around $13.6-32.9 \%$ and $29.2-40.6 \%$ when compared with the baseline case for heat transfer and friction loss, respectively.

As previous investigations, it is found that the delta winglet vortex generators can help to improve the thermal performance and heat transfer rate in the heating system. Moreover, the flow attack angle and the installing position of the vortex generators are an important factor for enhancing the heat transfer rate. Therefore, in the present study, the three dimensional numerical investigations on the flow configurations and heat transfer characteristics in fin-and-oval-tube compact heat exchanger with $\mathrm{V}$-tip pointing downstream delta-winglet pairs $(D D W P)$ are presented. The influences of the flow attack angle $\left(\theta=15^{\circ}, 30^{\circ}, 45^{\circ}\right.$ and $60^{\circ}$ ) and the distance between V-tip to the center of the oval tube in the transverse axis ( $a=3.77,4.77$ and $5.77 \mathrm{~mm}$ ) for the Reynolds number $(R e=500-2500)$ are studied.

\section{FLOW DESCRIPTIONS}

\subsection{Physical models}

According to Chu et al. (2009), Fig. 1 presents a fin-and-oval-tube compact heat exchanger which interesting in the current research work. The computational domain of the fin-and-oval-tube heat exchanger with $D D W P \mathrm{~s}$ is shown in Figs. 2 - 4. The delta winglet pairs are placed in front of the oval tubes with pointing downstream (V-tip downstream). The winglet and the channel height are identical, $H$. The aspect ratio $\Lambda(4 H / c)$ for delta winglet equals to 2 . The influences of the flow attack angle, $\theta=15^{\circ}, 30^{\circ}, 45^{\circ}$ and $60^{\circ}$, and the distances between V-tip and the center of oval tube, $a=3.77,4.77$ and $5.77 \mathrm{~mm}$ are investigated for $R e=500-2500$. The parameters of the computational domain are shown in table1.

To ensure a recirculation-free flow regime, the exit region is extended around $10 \mathrm{H}$. The entry region of the domain is developed by $10 H$ to maintain the uniform velocity.

\subsection{Boundary conditions and governing equations}

The flow is assumed to be steady laminar flow due to the low inlet velocity flowing though the small fin pitches. The fin thickness is taken into account in heat conduction. The considered fluid is an incompressible with constant properties. The boundary conditions are shown as follows.

1. At the entrance extended region, uniform velocity and temperature boundary condition are used at the inlet of the computational domain. Pressure outlet condition is employed at the outlet of the exit extended region. Symmetry condition is used at side boundaries of both extended regions.

2. For the fin-and-oval-tube region, no slip condition and constant wall temperature are used for a fin and tube surface. Symmetry condition is used at the both side boundaries.

The temperatures at the inlet of the air and tube wall are set at $340 \mathrm{~K}$ and $300 \mathrm{~K}$, respectively. The physical properties of the air are assumed to be constant at average bulk temperature. The inlet air velocities vary in the range 1.3 to $6.5 \mathrm{~m} / \mathrm{s}$ depended on Reynolds number, $R e=500-$ 2500 .

The governing equations for continuity, momentum and energy can be expressed as follows

Continuity equation:

$\frac{\partial}{\partial \mathrm{x}_{\mathrm{i}}}\left(\rho \mathrm{u}_{\mathrm{i}}\right)=0$

Momentum equation:

$\frac{\partial}{\partial \mathrm{x}_{\mathrm{i}}}\left(\rho \mathrm{u}_{\mathrm{i}} \mathrm{u}_{\mathrm{k}}\right)=-\frac{\partial \mathrm{P}}{\partial \mathrm{x}_{\mathrm{k}}}+\frac{\partial}{\partial \mathrm{x}_{\mathrm{i}}}\left[\mu\left(\frac{\partial \mathrm{u}_{\mathrm{k}}}{\partial \mathrm{x}_{\mathrm{i}}}\right)\right]$

Energy equation:

$\frac{\partial}{\partial \mathrm{x}_{\mathrm{i}}}\left(\rho \mathrm{u}_{\mathrm{i}} \mathrm{T}\right)=\frac{\partial}{\partial \mathrm{x}_{\mathrm{i}}}\left(\frac{\mathrm{k}}{\mathrm{C}_{\mathrm{p}}} \frac{\partial \mathrm{T}}{\partial \mathrm{x}_{\mathrm{j}}}\right)$

The important parameters in the present study are the Reynolds number $(R e)$, friction factor $(f)$, Nusselt number $(N u)$, and thermal enhancement factor $(T E F)$ which as follows

$\operatorname{Re}=\frac{\rho U_{c} D_{h}}{\mu}$

$\mathrm{f}=\frac{(2 \Delta \mathrm{P})}{\rho \mathrm{U}_{\mathrm{c}}^{2}}\left(\frac{\mathrm{D}_{\mathrm{h}}}{\mathrm{L}}\right)$

$\mathrm{Nu}=\frac{\mathrm{hD}_{\mathrm{h}}}{\mathrm{k}}$

$\mathrm{TEF}=\frac{\frac{\mathrm{Nu}}{\mathrm{Nu}_{0}}}{\left(\frac{\mathrm{f}}{\mathrm{f}_{0}}\right)^{\frac{1}{3}}}$

where, $N u$ and $N u$ are area-average Nusselt number and average Nusselt number of plain fin, respectively.

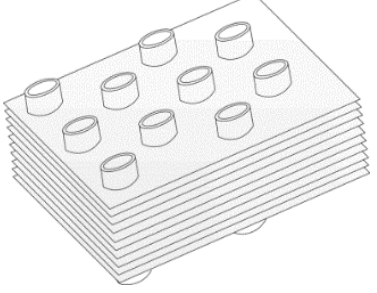

Fig. 1 Fin-and-oval-tube compact heat exchanger. 


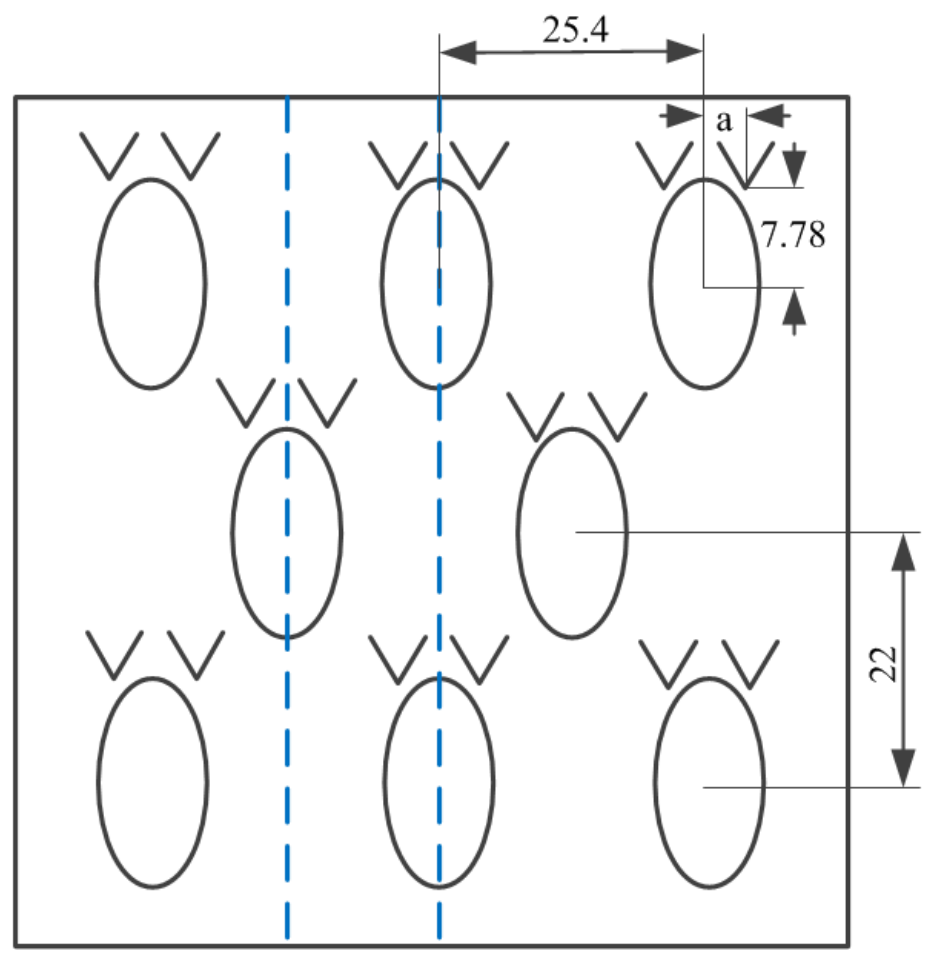

Fig. 2 Schematic diagram of computational domain.

Table 1 Parameters of the computational domains (Chu et al., 2009).

\begin{tabular}{|l|l|l|}
\hline Parameter & Symbol/unit & Value \\
\hline Channel height & $H / \mathrm{mm}$ & 3.2 \\
\hline Computational domain width & $B / \mathrm{mm}$ & 12.7 \\
\hline Computational domain length & $L / \mathrm{mm}$ & 64.4 \\
\hline Semi-major diameter of oval tube & $R_{\mathrm{a}} / \mathrm{mm}$ & 6.28 \\
\hline Semi- minor diameter of oval tube & $R_{\mathrm{b}} / \mathrm{mm}$ & 3.77 \\
\hline Winglet placed downstream from inlet & $Y / \mathrm{mm}$ & 17.92 \\
\hline Longitudinal tube pitch & $P_{\mathrm{l}} / \mathrm{mm}$ & 22 \\
\hline Spanwise tube pitch & $P_{\mathrm{s}} / \mathrm{mm}$ & 25.4 \\
\hline Fin thickness & $F_{\mathrm{t}} / \mathrm{mm}$ & 0.33 \\
\hline Fin pitch & $F_{\mathrm{p}} / \mathrm{mm}$ & 3.2 \\
\hline Number of tube row & $n$ & 3 \\
\hline Hydraulic diameter & $T_{\mathrm{in}} / \mathrm{K}$ & 3.63 \\
\hline Wall temperature & $u_{\mathrm{in}} / \mathrm{m} \mathrm{s}-1$ & 300 \\
\hline Inlet temperatures of air & & \\
\hline Frontal velocity & & \\
\hline
\end{tabular}




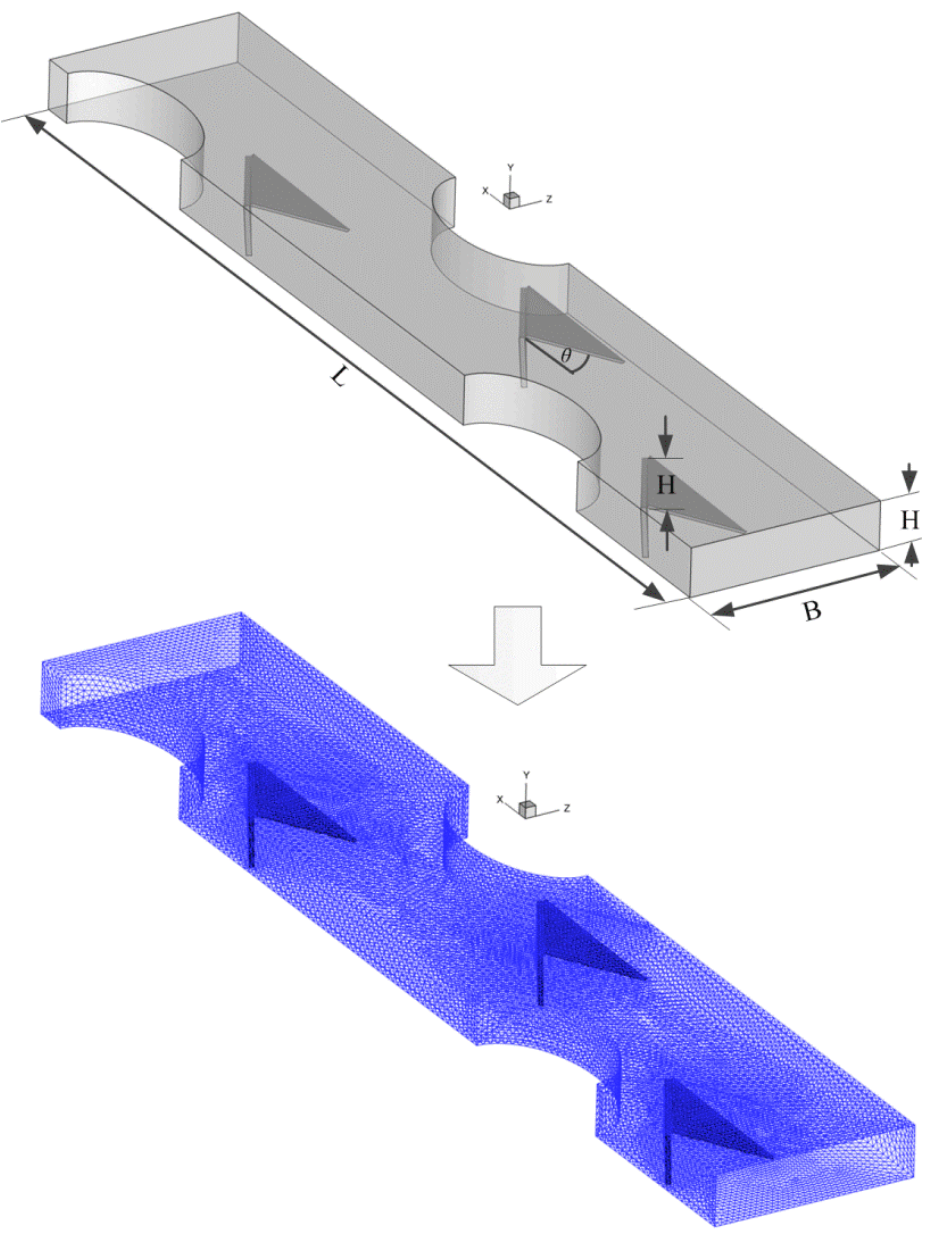

Fig. 3 Channel geometry and computational domain.

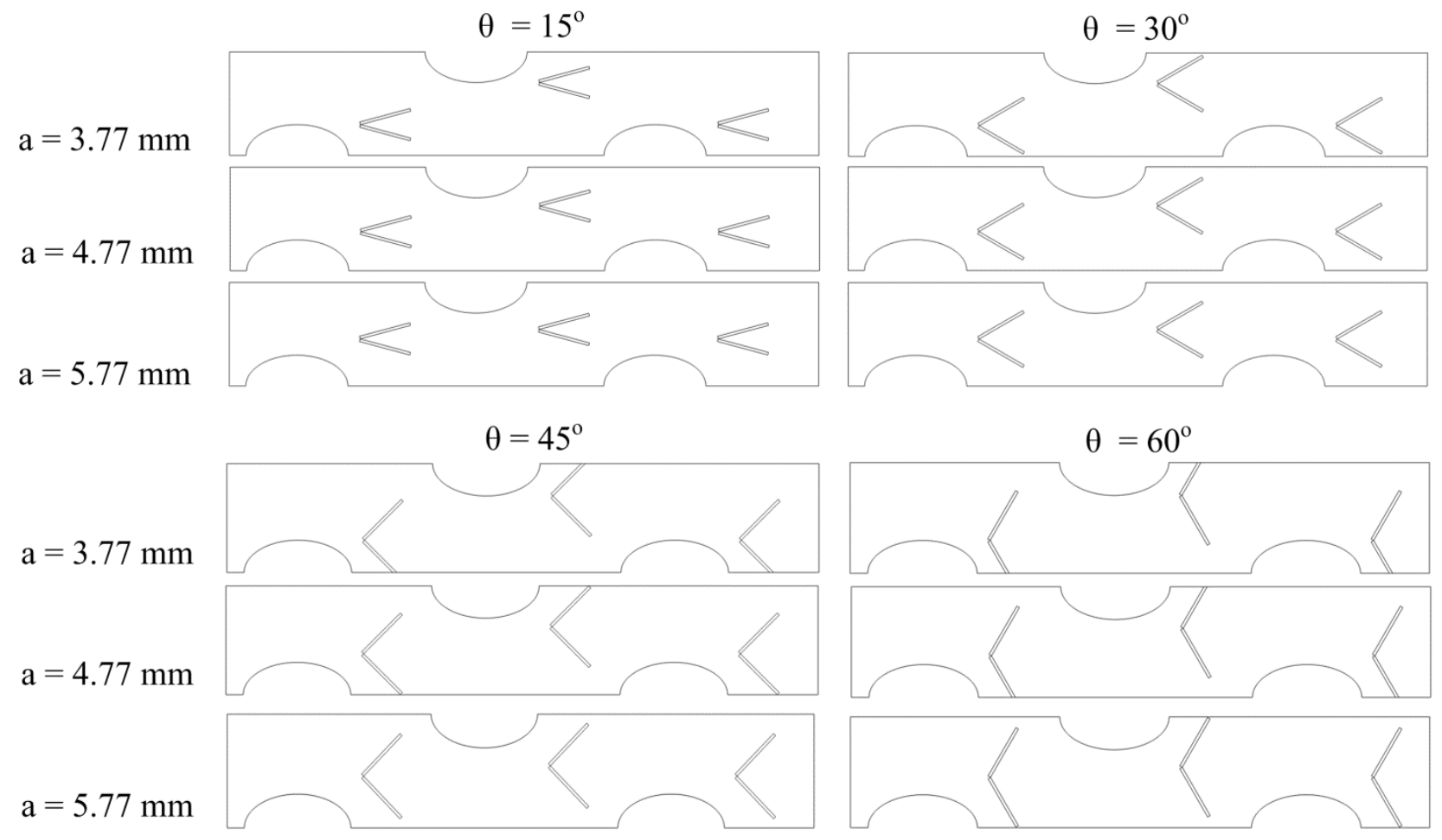

Fig. 4 Delta winglet configuration with various cases. 


\subsection{Method of research}

The computational fluid dynamics code is used for solving previous governing equations and the boundary conditions. The convective terms in the governing equations for momentum and energy are discretized with Power law scheme and QUICK scheme, respectively. The SIMPLE algorithm has been applied to the coupling among pressure and velocity. The convergence criterions for the velocities and temperature are arranged by the residual less than $10^{-5}$ and $10^{-9}$, respectively.

\section{RESULTS AND DISCUSSIONS}

\subsection{Verification of the computational domain}

The validations of the computational domain are separated into two parts; grid systems and compared with the experimental results. Grid independence is required to ensure the accuracy and validity of the numerical results. In order to validate the independency of solution on the grid, three difference grid systems which including 300000, 400000 and 500000 cells are investigated. The results on the three sets of grid found that the relative errors of the Nusselt number and friction factor are less than $1.1 \%$ and $1.2 \%$, respectively. Thus, there is no advantage for increase grid cells; the computational domain is applied with 300000 cells of grid number.

Except from the investigations on the grid systems, the flow configurations and heat transfer characteristics are compared with the experimental results (Chu et al., 2009) in terms of Nusselt number and pressure loss, respectively, as depicted in Fig. $5 a$ and $b$. As seen in the figures, the average discrepancy between the predicted and the experimental results is less than $9 \%$ and $4 \%$ for Nusselt number and the pressure loss, respectively. The good agreement with the validation results indicates that the computational domain is reliable to predict heat transfer characteristics and flow configurations in the fin-and-ovaltube heat exchangers.

\subsection{Flow topology}

The flow configurations for the $D D W P$ s in the fin-and-oval-tube heat exchanger are presented in terms of streamlines in transverse planes and the three dimensional streamlines flow over the $D D W P$ s as Figs. $6-8$. The numerical results can be described into two parts; the influence of the flow attack angle and distance between oval tube center and V-tip.

The effects of the flow attack angle, Figs. $6 a, b, c$ and $d$ illustrate the streamlines in transverse planes for flow attack angles, $\theta=15^{\circ}, 30^{\circ}, 45^{\circ}$ and $60^{\circ}$, at $R e=1000$ and $a=3.77 \mathrm{~mm}$, respectively. The streamlines in transverse planes for each case are located at the $\mathrm{V}$ - tip and the winglet leading edges $(W L E)$. As figures, there are found that the $D D W P$ s produce the vortex flows as clearly seen at the $\mathrm{V}$-tip planes for all cases. The differences of the flow attack angle result in the variations of the vortex flow intensity and the vortex core locations. It is seen that the rise of the flow attack angle leads to the increase in vortex strength; the $60^{\circ} D D W P$ performs the highest of the vortex intensity while the $15^{\circ}$ $D D W P$ provides the lowest.

Effects of the distance between V-tip and oval tube center, Figs. 7a, $b$ and $c$ show the streamlines in transverse planes for $30^{\circ} \mathrm{DDWP}$ at $\operatorname{Re}=$ 1500 and $a=3.77,4.77$ and 5.77, respectively. In general, the flow configurations are appearing similar, but, the cores of the vortex flows are changed depending on the positions of the $D D W P \mathrm{~s}$. Due to the streamlines in transverse planes cannot describe the influence of the distance between $\mathrm{V}$-tip and oval tube center, therefore, the effect of the distance from V-tip to the center of the oval tube will be concluded by graph for the variance of Nusselt number and friction factor in the next part.

The streamlines flow over the $D D W P$ in the test section is presented in Fig. 8 for the $30^{\circ}$ of the flow attack angle at $R e=1000$ and $a=3.77$ $\mathrm{mm}$. As seen from the figure, the fluid flows become swirling when the flow passing the $W L E$ before impinge at the leading curve of the oval tube. This phenomenon is a key for enhancing the heat transfer rate and thermal performance in the compact heat exchanger.

In addition, the presences of the vortex flows which created by $D D W P$ s can help with the mixing of the fluid flow that lead to the increase in heat transfer rate over the tube walls. However, the use of the $D D W P$ on only increases in the heat transfer, but also increases in pressure loss in the fin-and-oval-tube heat exchanger.

\subsection{Velocity fields}

In this part, the velocity profiles in the fin-and-oval-tube heat exchanger with $D D W P$ s are displayed in the form of the local distributions of the $\mathrm{x}$-velocity in the middle cross section plane. The influences of the flow attack angles and the distance from V-tip to the center of the oval tube, $a$, values are also presented.

Figs. 9 and 10 illustrate the local distributions of the $x$-velocity on the middle cross section (parallel to the $\mathrm{x}-\mathrm{z}$ plane) at various the flow attack angles and the $a$ value, respectively. It can be seen in the figures that the velocity fields provide uniformly at the inlet regions of the test sections for all cases. When the fluid flows passing the $D D W P$ s, the velocity performs higher, especially, at the middle regimes between the first pairs and the third pairs for the DDWPs and on both two sides regimes of the second pairs. The numerical results are according to the flow configurations of the previous part.

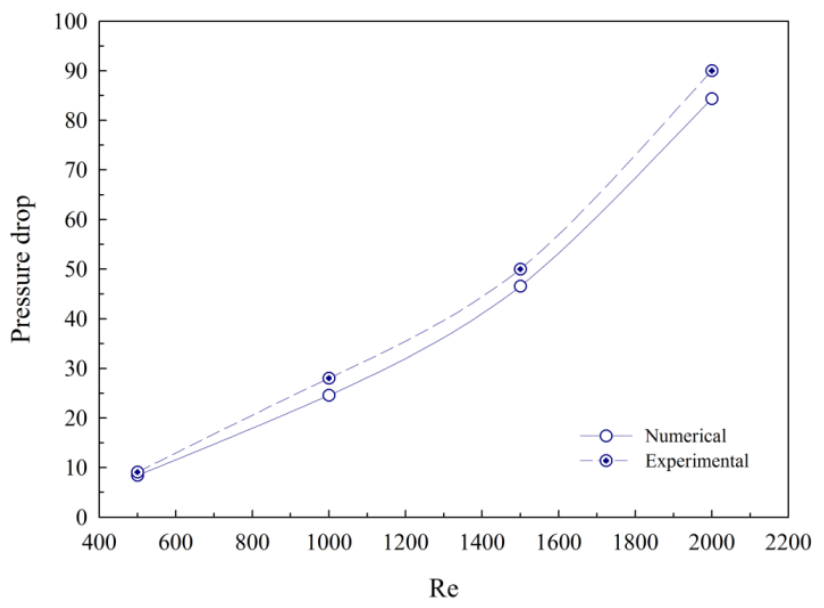

(b)

(a)

Fig. 5 Experimental-numerical comparison for model validations (a) Nusselt number and (b) pressure drop 


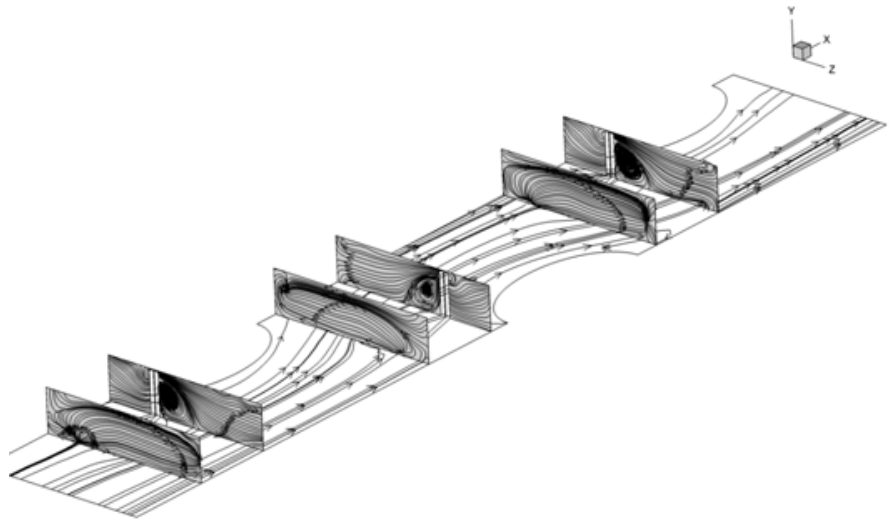

(a)

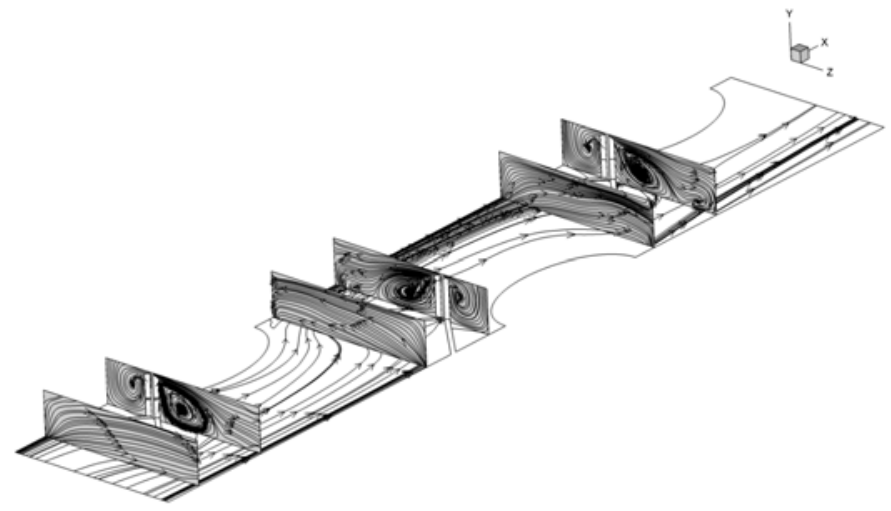

(c)

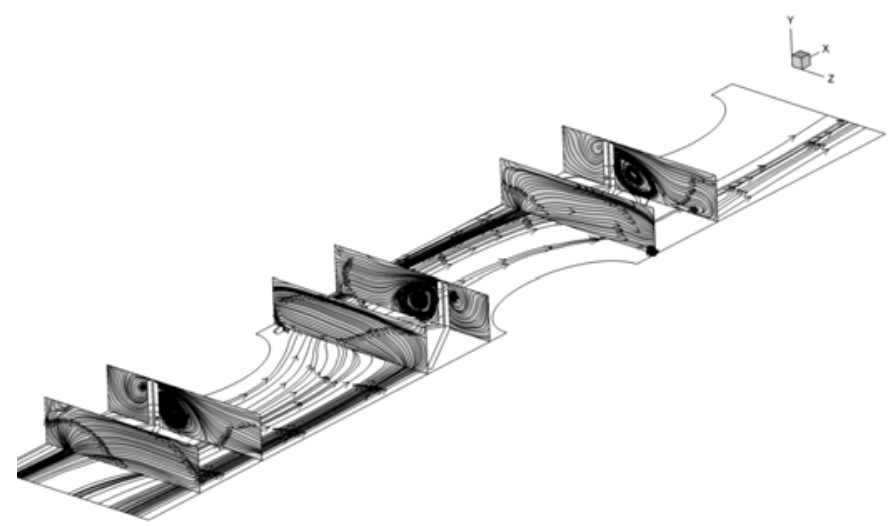

(b)

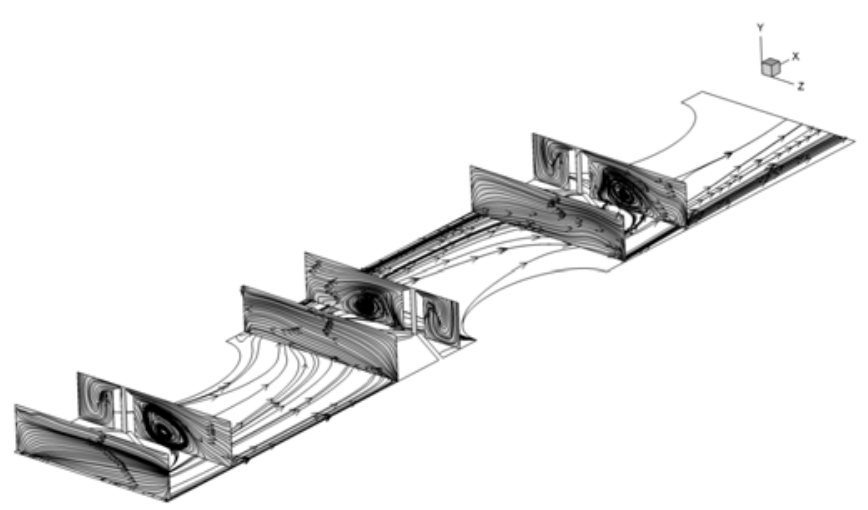

(d)

Fig. 6 Streamlines in transverse planes for (a) $15^{\circ}$, (b) $30^{\circ}$, (c) $45^{\circ}$ and (d) $60^{\circ}$ at $R e=1000$ and $a=3.77 \mathrm{~mm}$.

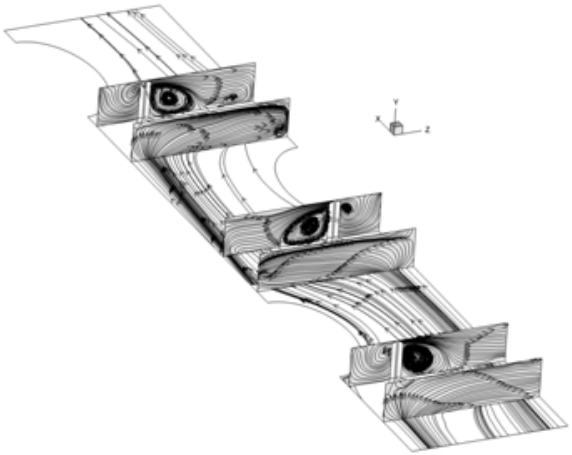

(a)

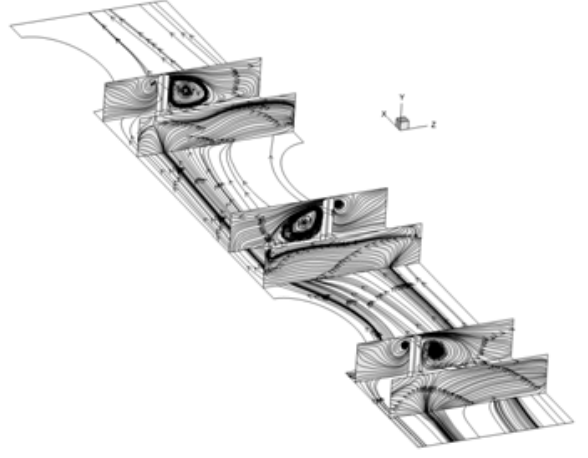

(b)

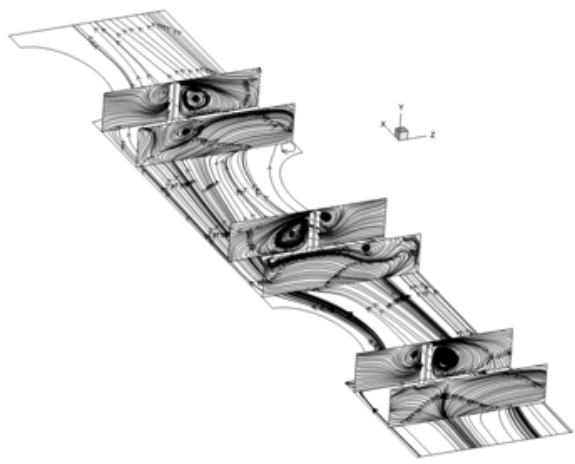

(c)

Fig. 7 Streamlines in transverse planes for (a) $a=3.77 \mathrm{~mm}$, (b) $a=4.77 \mathrm{~mm}$ and (c) $a=5.77 \mathrm{~mm}$ at $R e=1500$ and $\theta=30^{\circ}$. 

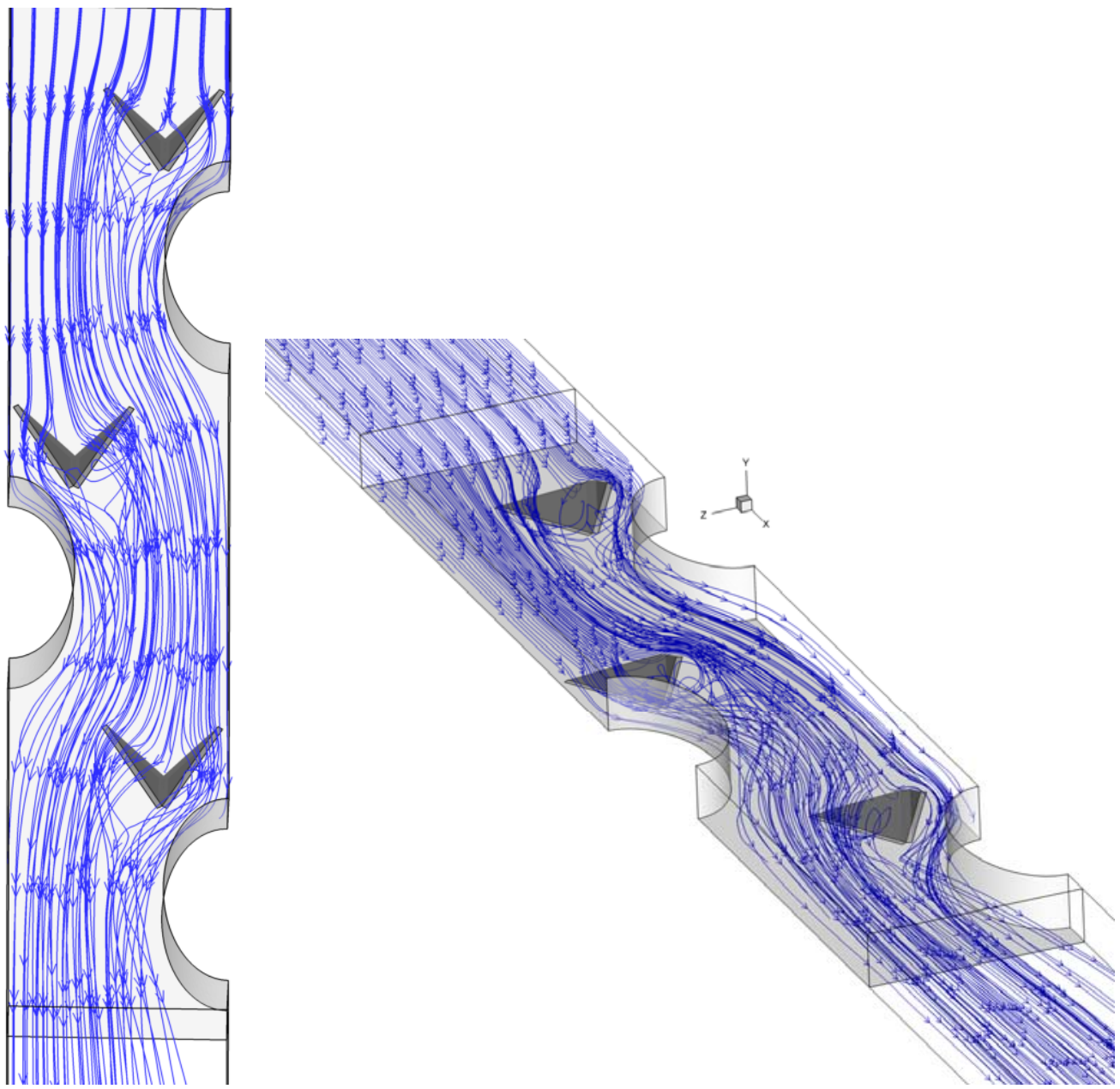

Fig. 8 Streamlines in three dimensions for $a=3.77 \mathrm{~mm}$ at $R e=1500$ and $\theta=30^{\circ}$.

The local distributions of the $\mathrm{x}$-velocity on the middle cross section for the flow attack angle, $\theta=15^{\circ}, 30^{\circ}, 45^{\circ}$ and $60^{\circ}$, at $R e=1000$ and $a$ $=3.77 \mathrm{~mm}$ are presented in the Figs. $9 a, b, c$ and $d$, respectively. It is found that the differences of the flow attack angle have an effect of the velocity fields. The higher of the flow attack angle lead to the increase in the velocity values. It is clearly seen that the $\theta=60^{\circ}$ performs the most different of the velocity field, the large blue contours are found behind the $D D W P$ s regimes when compared with other cases. The velocity distributions are found consistently in the case of $\theta=15^{\circ}$. The rise of the flow attack angle leads to higher of the velocity values. The reason of this may be that the high flow attack angle effects for the increasing turbulence intensity or vortex strength. Although, the high flow attack angle, $\theta=60^{\circ}$, leads to the increase in heat transfer rate, but the better velocity distributions are found at the low flow attack angle, $\theta$ $=15^{\circ}$.

Figs. $10 a, b$ and $c$ present the local distributions of the $\mathrm{x}$-velocity at the middle cross section of the flow attack angle, $\theta=30^{\circ}$ and $R e=1500$ for $a=3.77,4.77$ and $5.77 \mathrm{~mm}$, respectively. In general, the velocity distributions for all cases, perform nearly profile; the uniform velocity appears in the entry regions of the test sections and performs increase when passing the $D D W P$ s. The variations of the velocity profiles depended on the position of the $D D W P$ in the test section. It seems that the distance between $\mathrm{V}$-tip and oval tube center, $a=3.77 \mathrm{~mm}$ gives the highest values of the velocity while the distance between V-tip and oval tube center, $a=4.77$ and $5.77 \mathrm{~mm}$ show nearly values of the velocity. Additionally, the increase in the distance between V-tip and oval tube center results in the augmenting velocity values.

\subsection{Heat transfer characteristics}

The heat transfer characteristics in the fin-and-oval-tube heat exchanger with $D D W P$ s are considered from the local distributions of the temperature and the local Nusselt number over the tube walls.

Figs. 11 and 12 show the temperature contours at the middle cross sections in the test section with $D D W P$ s at various the flow attack angles and the distance between V-tip and oval tube center values, respectively. In general, the local distributions of the temperature for all cases are nearly profiles; the uniform contours of $340 \mathrm{~K}$ are found in the inlet regimes of all test sections and the lower temperature values are found at behind the oval tube regimes.

Figs. $11 a, b, c$ and $d$ present the local distributions of the temperature in the test sections with $D D W P$ s for the flow attack angle, $\theta=15^{\circ}, 30^{\circ}$, $45^{\circ}$ and $60^{\circ}$, respectively, at $R e=1000$ and $a=3.77 \mathrm{~mm}$. Considering at behind the oval tubes, the differences of the contour temperature are found, especially, for the $\theta=15^{\circ}$. It is seen that the $\theta=15^{\circ}$ performs the best mixing of the fluid flow at behind the oval tube while the $\theta=$ $30^{\circ}, 45^{\circ}$ and $60^{\circ}$ give better mixing of the fluid flow when passing the third pairs of the $D D W P$ s.

The temperature contours of the $\theta=30^{\circ}, R e=1500$ at the middle cross section for $a=3.77,4.77$ and $5.77 \mathrm{~mm}$ are illustrated in Figs. $12 a$, $b$ and $c$, respectively. As seen, the case of $a=3.77 \mathrm{~mm}$ performs better mixing of the fluid flow at behind the third pairs of the DDWPs when comparing with the cases of $a=4.77$ and $5.77 \mathrm{~mm}$. The case of $a=$ $5.77 \mathrm{~mm}$, the better mixing of the fluid flow is found at behind the oval tube. Additionally, the case of $a=3.77 \mathrm{~mm}$ gives the best mixing of the fluid flow in comparison with other $a$ values. 
The local Nusselt number distributions over the tube walls for $D D W P$ s in the test sections are shown in Figs. 13 and 14 at various the flow attack angles and the $a$ value, respectively. It is found that the peaks regimes of the heat transfer rate are found at the leading curve of the oval tube walls for all cases due to the impinging of the jets in these areas as described in the Fig. 8 in the flow topology part. Additionally, the impinging jet of the fluid flow on the leading curve of the oval tube wall is a main factor for heat transfer augmentation.

Figs. 13a, $b, c$ and $d$ present the local Nusselt number contours of the $D D W P$ s in the fin-and-oval-tube heat exchanger for the flow attack angle, $\theta=15^{\circ}, 30^{\circ}, 45^{\circ}$ and $60^{\circ}$, respectively, at $R e=1000$ and $a=3.77$ $\mathrm{mm}$. It is appeared that the $\theta=60^{\circ}$ performs the highest heat transfer rate while the $\theta=15^{\circ}$ gives the lowest values of the heat transfer rate. This means that the larger flow attack angle results in the higher vortex flow intensity that leads to the augmenting heat transfer rate in the compact heat exchanger.

Figs. $14 a, b$ and $c$ illustrate the contours of the Nusselt number at $\theta=$ $30^{\circ}$, $R e=1500$ for $a=3.77,4.77$ and $5.77 \mathrm{~mm}$, respectively, for $D D W P$ s in the compact heat exchanger. The similar profiles or very close configurations of the local Nusselt number contours for all cases are appearing, so, the effect of the distance values, $a$, on heat transfer characteristics cannot consider from the local Nusselt number contours. The influence of the distance values on heat transfer will be concluded in the form of the Nusselt number values in the part of the performance evaluation.

\subsection{Performance evaluation}

There are three parts in this section for considering; heat transfer, pressure drop and the thermal performance. The performance evaluations in the fin-and-oval-tube heat exchanger with $D D W P$ s are presented in terms of the variations of the Nusselt number, the Nusselt number ratio $\left(N u / N u_{0}\right)$, the friction factor, the friction factor ratio $\left(f / f_{0}\right)$ and the thermal enhancement factor $(T E F)$ with Reynolds number as depicted in Figs. 15, 16, 17, 18 and 19, respectively.

Figs. $15 a, b$ and $c$ show the variations of the Nusselt number with Reynolds number at various the flow attack angles for $a=3.77,4.77$ and $5.77 \mathrm{~mm}$, respectively. The Nusselt number tends to increase with the increasing Reynolds number for all cases. The flow attack angle, $\theta$ $=60^{\circ}$ case performs the highest values of the Nusselt number while the lowest values are found at $\theta=15^{\circ}$ for all a values. The Nusselt number values are around $6.6-24,6.8-20$ and $7-19$ for $a=3.77,4.77$ and $5.77 \mathrm{~mm}$, respectively, for $D D W P$ in range $R e=500-2500$ and $\theta=15^{\circ}$ $-60^{\circ}$.

The variations of the $N u / N u_{0}$ are presented in the Figs. $16 a, b$ and $c$ for $a=3.77,4.77$ and $5.77 \mathrm{~mm}$, respectively. In range $500 \leq R e \leq 2000$, the $N u / N u$ tends to increase with the rise of Reynolds number and then slightly decrease when $R e>2000$ for $a=3.77$ and $4.77 \mathrm{~mm}$, and for $a=$ $5.77 \mathrm{~mm}$ at $\theta=15^{\circ}$ and $30^{\circ}$. At $a=5.77 \mathrm{~mm}$ for $\theta=45^{\circ}$ and $60^{\circ}$, the $N u / N u_{0}$ increase in range $500 \leq R e \leq 1500$ after that the $N u / N u_{0}$ slightly decrease. The use of the $D D W P$ can help to increase heat transfer in the fin-and-oval-tube heat exchanger around $1.1-1.59,1.12-1.56$ and $1.15-1.50$ times over the plain fin with no $D D W P$ for $a=3.77,4.77$ and $5.77 \mathrm{~mm}$, respectively. The optimum points are found at $R e=2000$ and $\theta=60^{\circ}$ for $a=3.77$ and $4.77 \mathrm{~mm}$ while the maximum enhancing heat transfer is found at $R e=1500$ and $\theta=60^{\circ}$ for $\theta=5.77 \mathrm{~mm}$. In addition, the increase in the flow attack angle and the decrease in $a$ value perform higher heat transfer rate in the heat exchanger with $D D W P$ s. This is because the higher turbulence intensity or vortex strength which occurring at a high flow attack angle and at the lower distance form V-tip to the center of the oval tube.

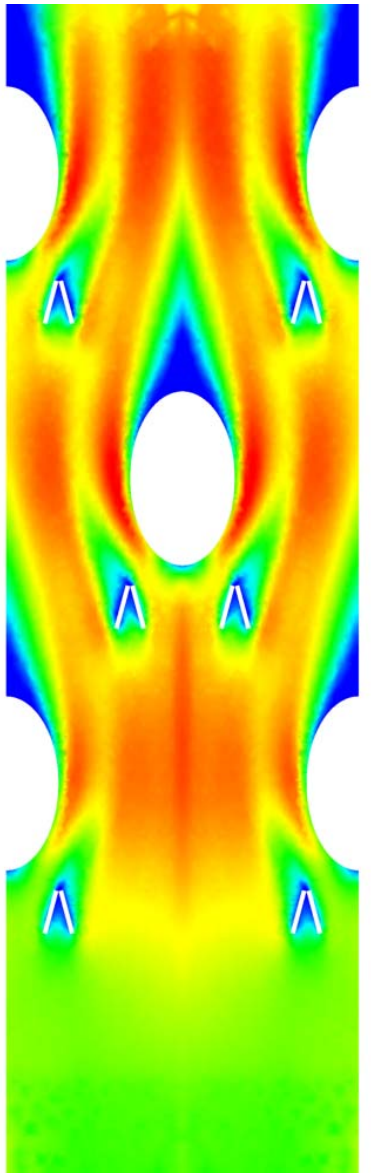

(a)

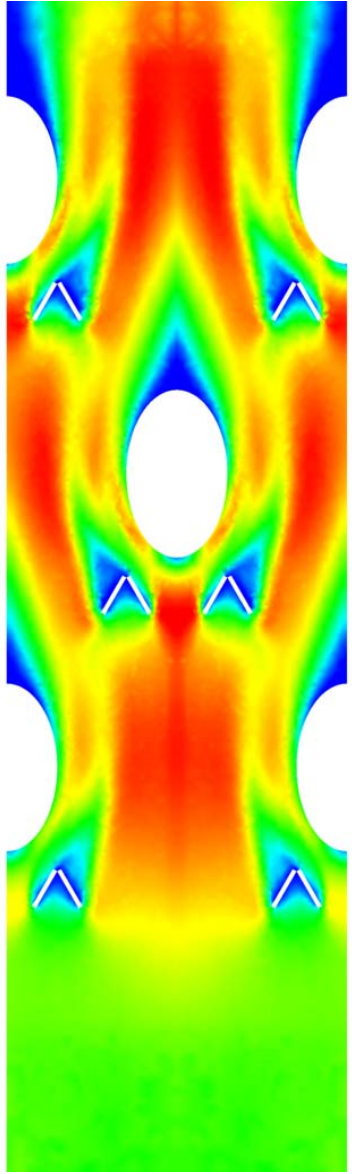

(b)

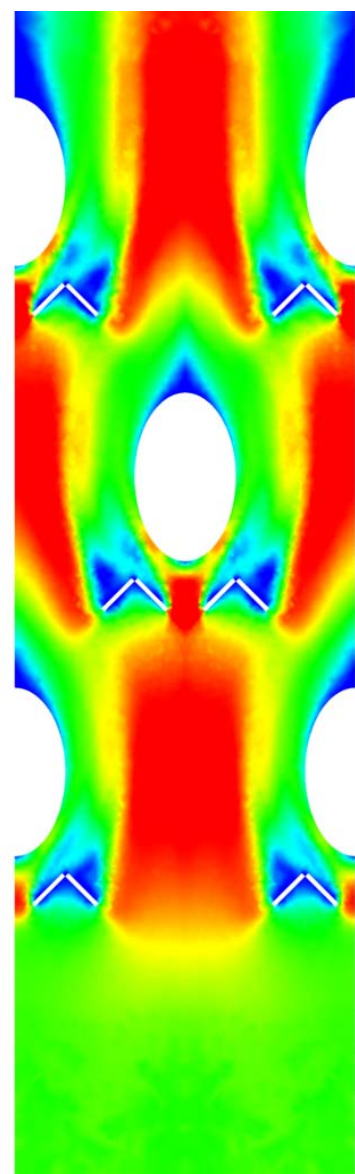

(c)

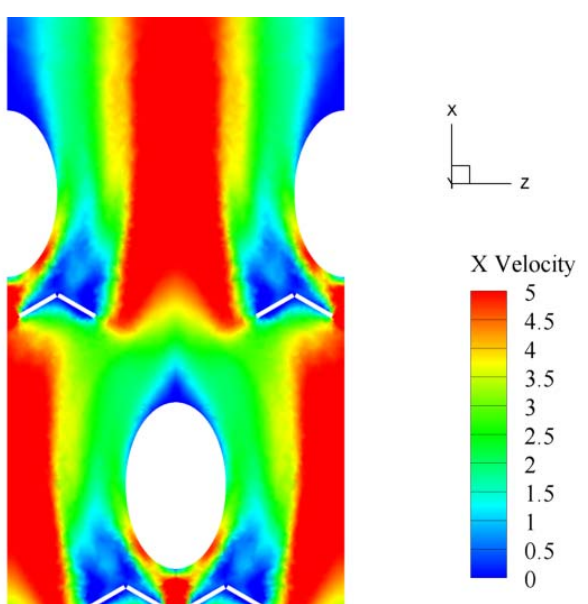

(d)

Fig. 9 Contours of x-velocity for (a) $15^{\circ}$, (b) $30^{\circ}$, (c) $45^{\circ}$ and (d) $60^{\circ}$ at $R e=1000$ and $a=3.77 \mathrm{~mm}$. 


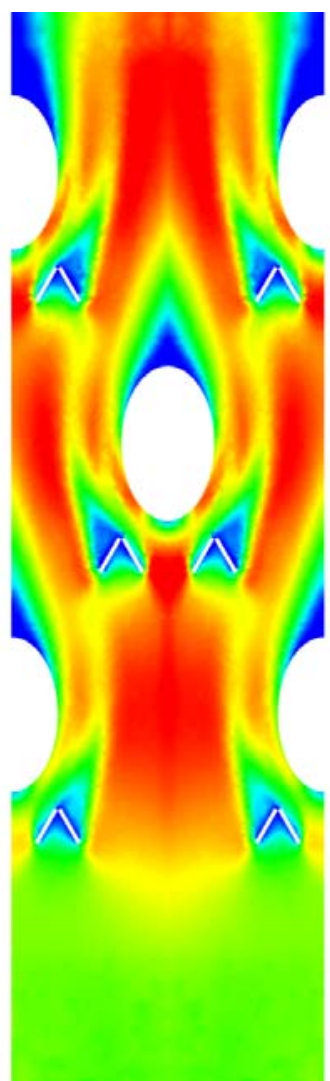

(a)

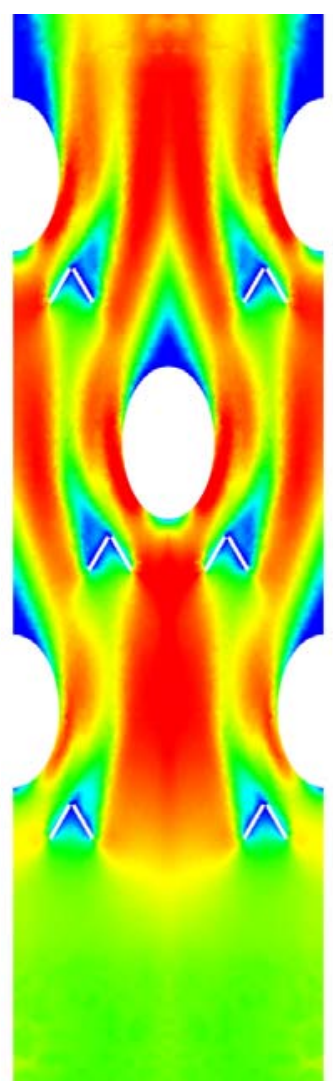

(b)

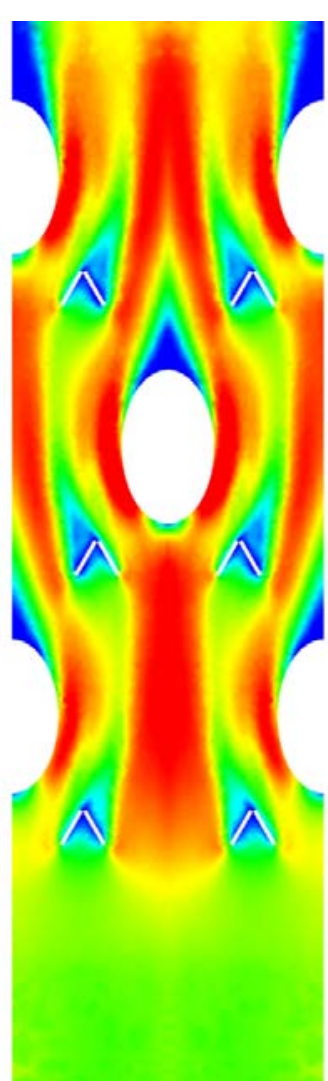

(c)

Fig. 10 Contours of x-velocity for (a) $a=3.77 \mathrm{~mm}$, (b) $a=4.77 \mathrm{~mm}$ and (c) $a=5.77 \mathrm{~mm}$ at $R e=1500$ and $\theta=30^{\circ}$.

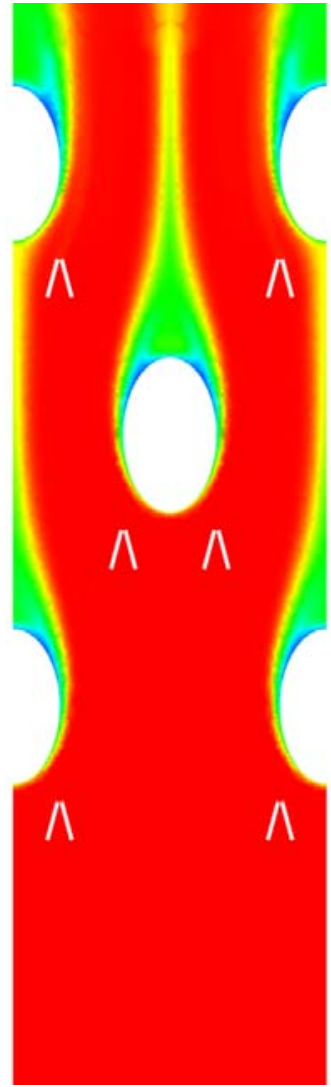

(a)

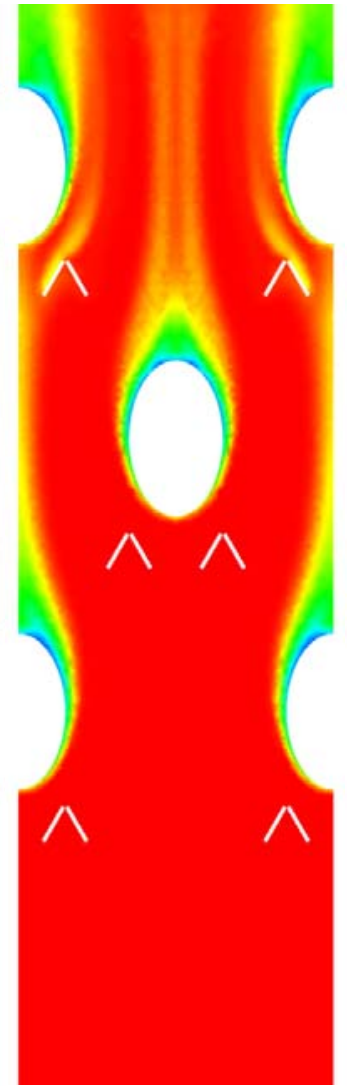

(b)

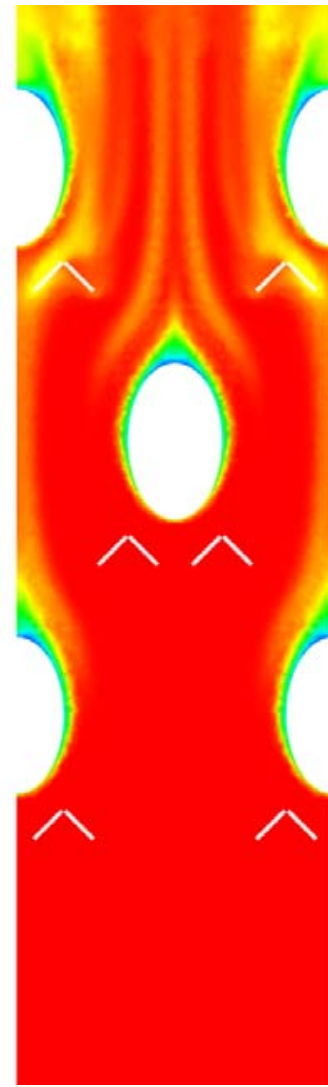

(c)

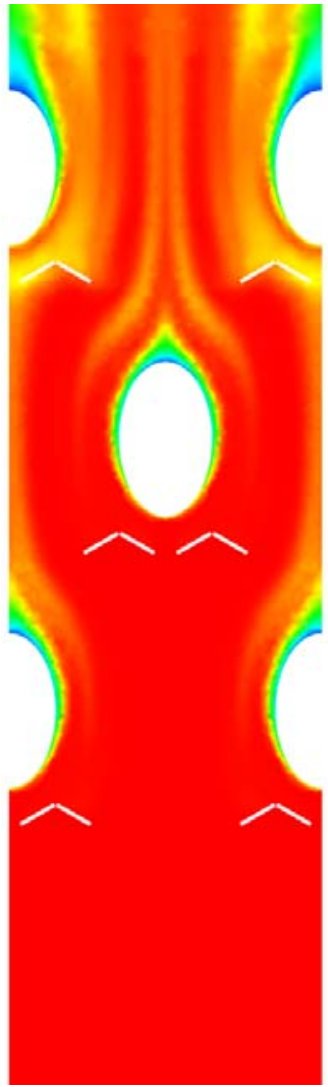

(d)

Fig. 11 Contours of temperature for (a) $15^{\circ}$, (b) $30^{\circ}$, (c) $45^{\circ}$ and (d) $60^{\circ}$ at $R e=1000$ and $a=3.77 \mathrm{~mm}$. 


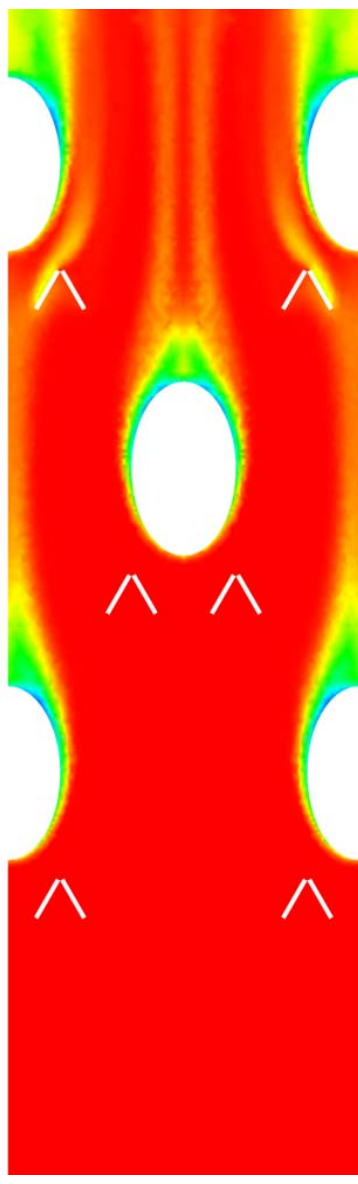

(a)

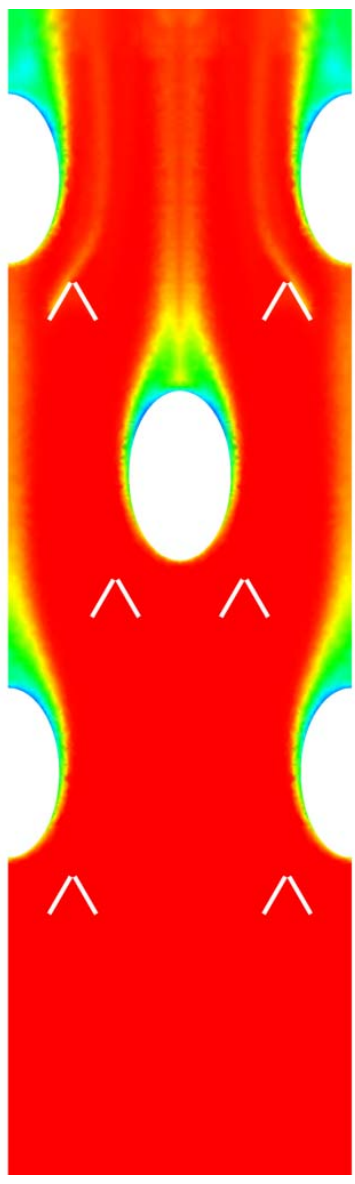

(b)

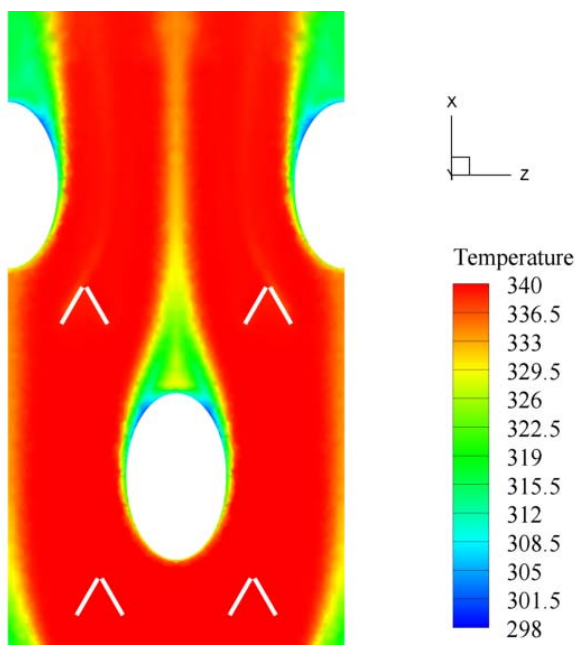

298

Fig. 12 Contours of temperature for (a) $a=3.77 \mathrm{~mm}$, (b) $a=4.77 \mathrm{~mm}$ and (c) $a=5.77 \mathrm{~mm}$ at $R e=1500$ and $\theta=30^{\circ}$.

The use of the $D D W P$ s in the compact heat exchanger leads to the increasing in the friction factor over the smooth plain fin. Figs. $17 a, b$ and $c$ illustrate the variations of the friction factor with Reynolds number for fin-and-tube heat exchanger with $D D W P$ s at $a=3.77,4.77$ and $5.77 \mathrm{~mm}$, respectively. As seen in the figures, the friction factor tends to decrease with increasing the Reynolds number for all cases. In range studied, the friction factor is found to be about $0.06-0.24$ depended on the flow attack angle, $a$ value and the Reynolds number.

The $f / f_{0}$ values with the Reynolds number for $a=3.77,4.77$ and $5.77 \mathrm{~mm}$ are presented in Figs. $18 a, b$ and $c$, respectively, at various the flow attack angles. The use of the $D D W P$ s performs higher friction factor than the smooth plain fin for all cases. For $\theta=45^{\circ}$ and $60^{\circ}$, the $f l f_{0}$ provides increased with the increasing Reynolds number for all $a$ values. For $\theta=15^{\circ}$ and $30^{\circ}$, the $f l f_{0}$ tends to increase when the Reynolds number increasing from 500 to 1000, but performs slightly decrease when $R e>1000$. The $f l f_{0}$ values are found to be around $1.6-$ 4.4, $1.6-4.25$ and $1.6-4.25$ for $a=3.77,4.77$ and $5.77 \mathrm{~mm}$, respectively. Additionally, the rise of the flow attack angle provides the increase in the friction factor while the difference between $a$ value performs nearly values of the friction factor.

The thermal performance is considered in term of the thermal enhancement factor, TEF, which referred from Sriromreun et al., 2012. The $T E F$ value is calculated from the increasing of the heat transfer rate and also the rising friction factor in the heating system when considering the current test section as rectangular channel. Figs. 19a, $b$ and $c$ show the variations of the TEF with the Reynolds number at various the flow attack angles for $a=3.77,4.77$ and $5.77 \mathrm{~mm}$, respectively. The $T E F$ varies in the range $0.91-1.09$ depended on the flow attack angle, the Reynolds number and $a$ value of the $D D W P$ in the compact heat exchanger. The optimum $T E F$ values are found to be about 1.075, 1.075 and 1.09 at $\operatorname{Re}=2500,2000$ and 2500 and $\theta=30^{\circ}$, $30^{\circ}$ and $15^{\circ}$ for $a=3.77,4.77$ and $5.77 \mathrm{~mm}$, respectively. Although, the $\theta=45^{\circ}$ and $60^{\circ}$ perform higher heat transfer rate than the $\theta=15^{\circ}$ and $30^{\circ}$, but also produces very enlarge pressure loss, therefore, almost the optimum point of the $T E F$ is found at $\theta=30^{\circ}$ which provides the optimum value on both the heat transfer rate and the friction factor augmentation.

\section{CONCLUSIONS}

In this article, 3D numerical simulations are examined to study the flow configurations and heat transfer characteristics in the fin-and-oval-tube heat exchangers with $D D W P$ s. The influences of the geometrical parameters with respect to fin-and-oval-tube heat exchangers with $D D W P$ s; the flow attack angle $\left(\theta=15^{\circ}, 30^{\circ}, 45^{\circ}\right.$ and $\left.60^{\circ}\right)$ and the a value ( $a=3.77,4.77$ and $5.77 \mathrm{~mm}$ ) are studied for the Reynolds number based on the hydraulic diameter, $R e=500-2500$. The major conclusions are drawn as follows:

- The use of the $D D W P$ s in the fin-and-oval tube heat exchanger can help to create the vortex flow or swirl flow and also the impinging of the fluid flow at the leading curve of the oval tubes. The fluid flow phenomenon leads to the increase in the heat transfer rate in the compact heat exchanger but also enhance in the friction loss.

- The rise of the flow attack angle leads to the increase in the heat transfer rate and friction factor. The $\theta=60^{\circ}$ performs the highest on both heat transfer and the friction factor while the $\theta=15^{\circ}$ provides the lowest values. Due to the high of the flow blockage for $\theta=60^{\circ}$, when considering in cross sectional area of the test section, that leads to the difference of the pressure between before and after of the DDWPs. The higher different values of the pressure are the main reason to produce the strength vortex flow over the test section in comparison with other 


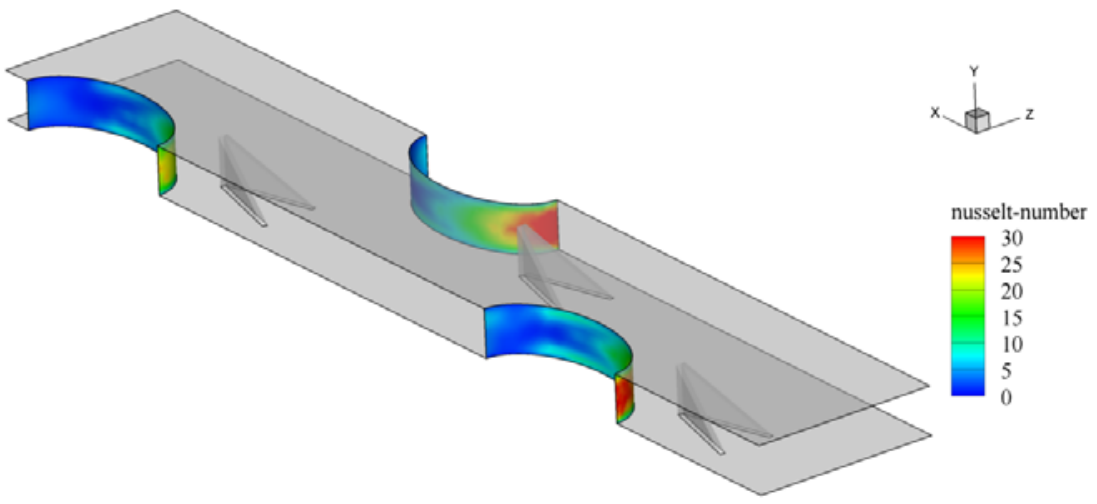

(a)

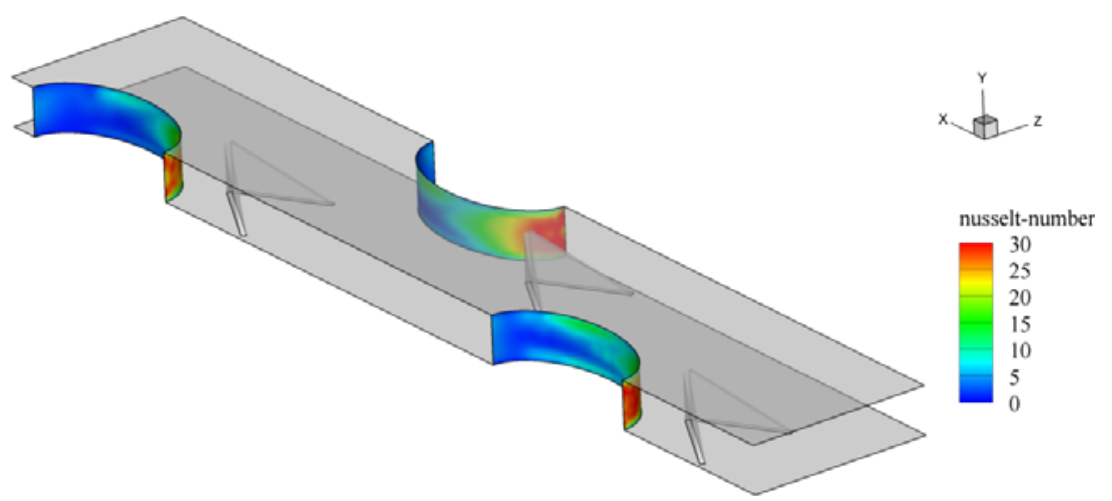

(b)

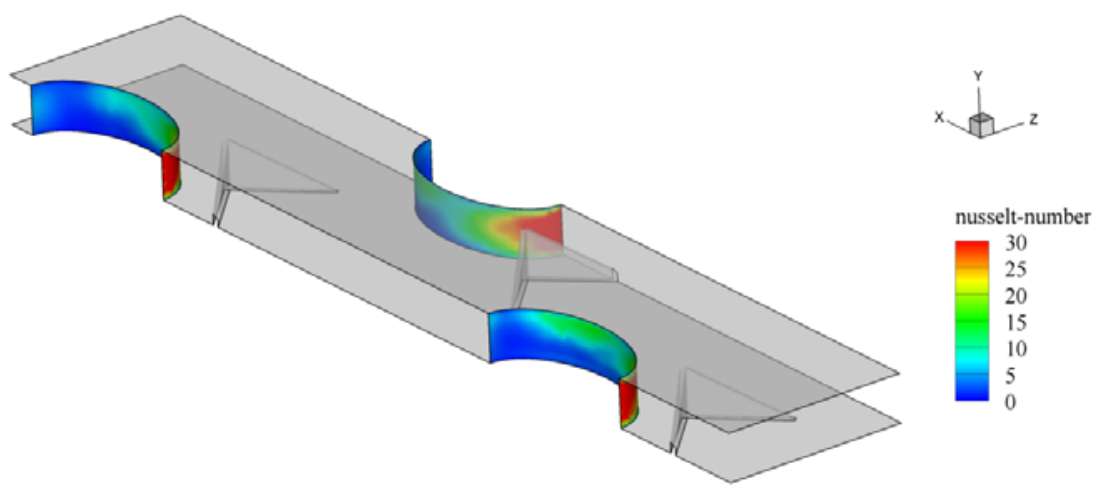

(c)

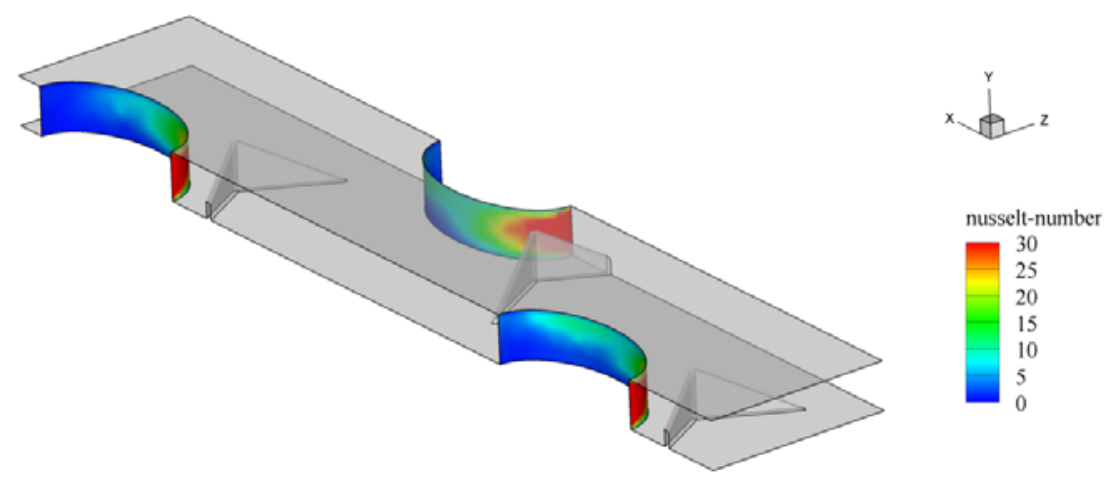

(d)

Fig. 13 Contours of local Nusselt number at oval tube walls for (a) $15^{\circ}$, (b) $30^{\circ}$, (c) $45^{\circ}$ and (d) $60^{\circ}$ at $R e=1000$ and $a=3.77 \mathrm{~mm}$. 


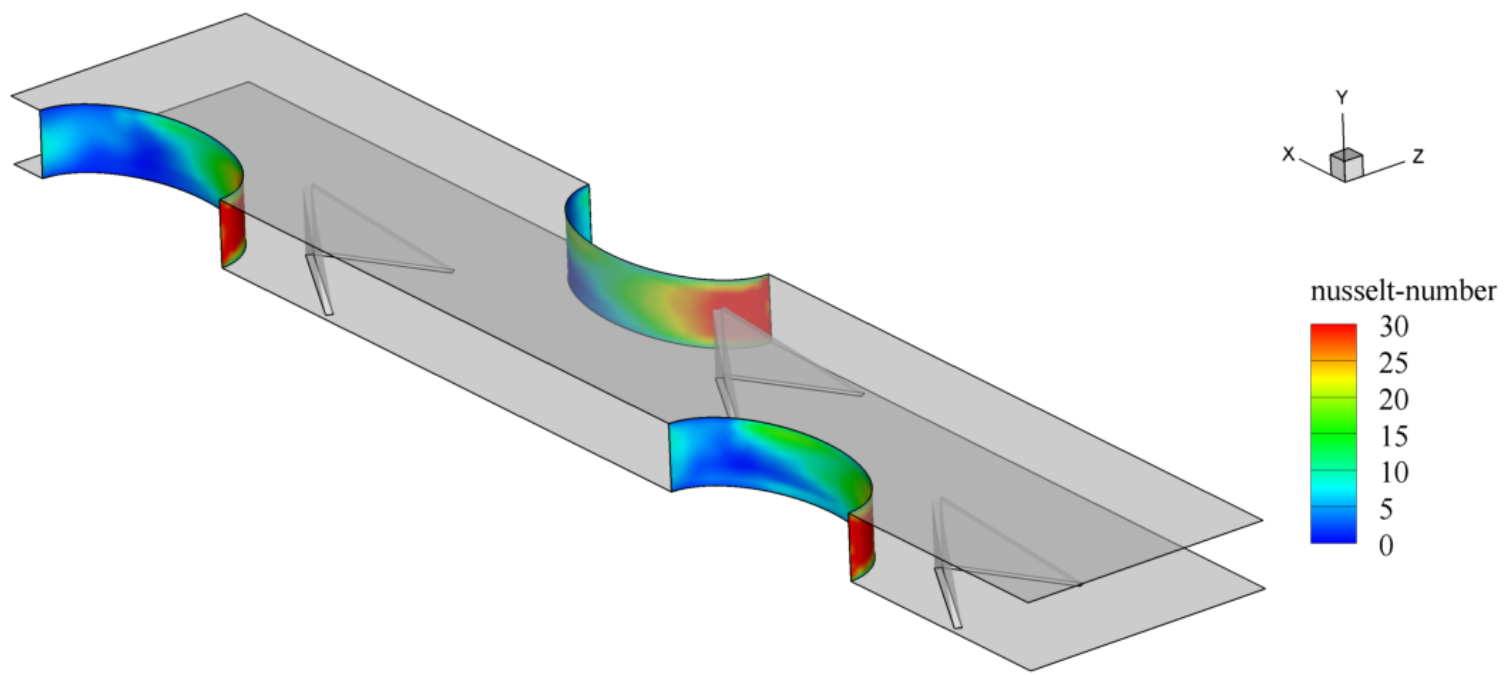

(a)
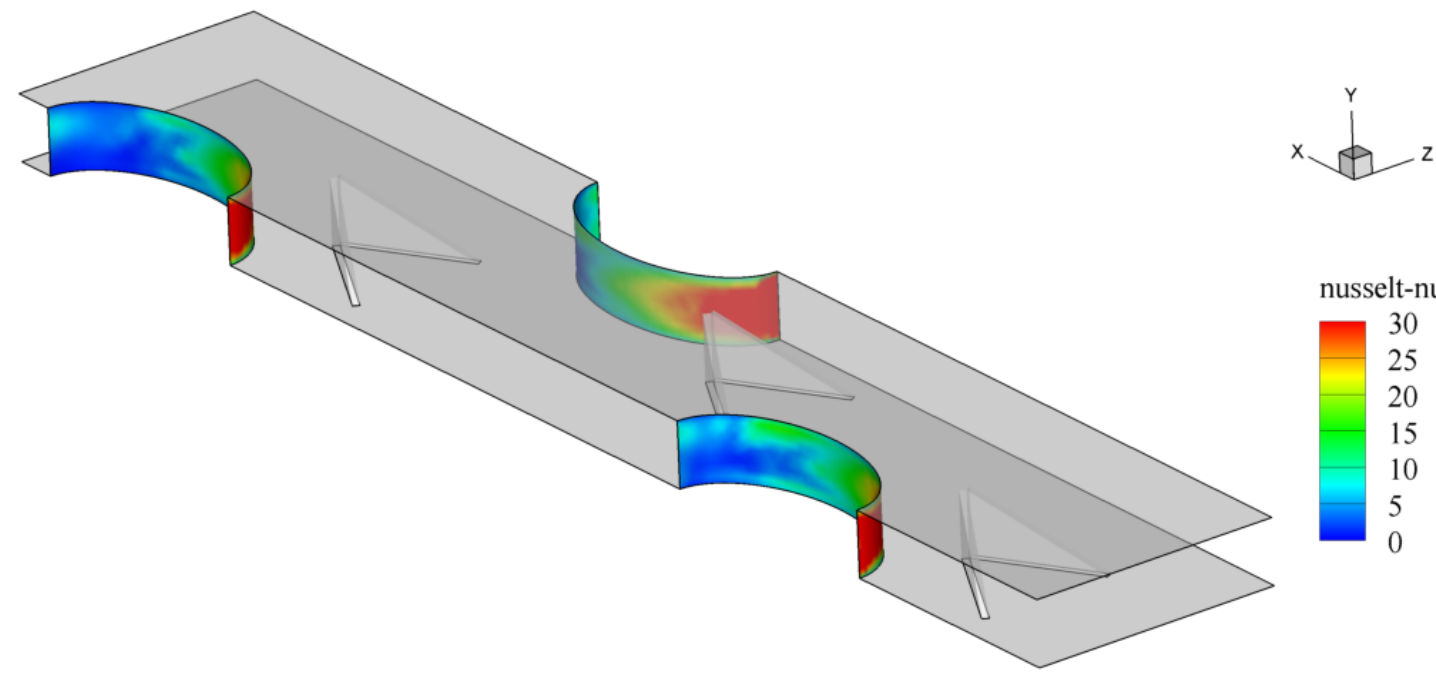

(b)

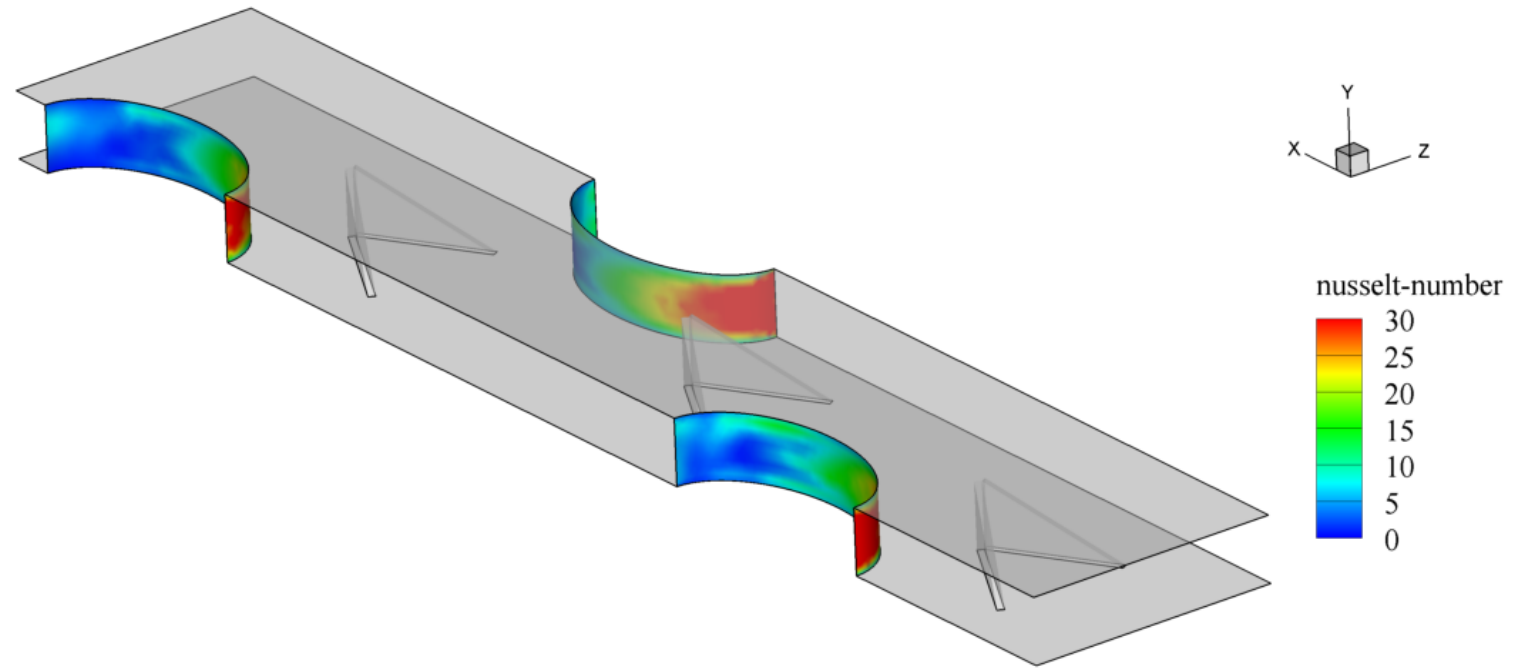

(c)

Fig. 14 Contours of local Nusselt number at oval tube walls for (a) $a=3.77 \mathrm{~mm}$, (b) $a=4.77 \mathrm{~mm}$ and (c) $a=5.77 \mathrm{~mm}$ at $R e=1500$ and $\theta=30^{\circ}$. 


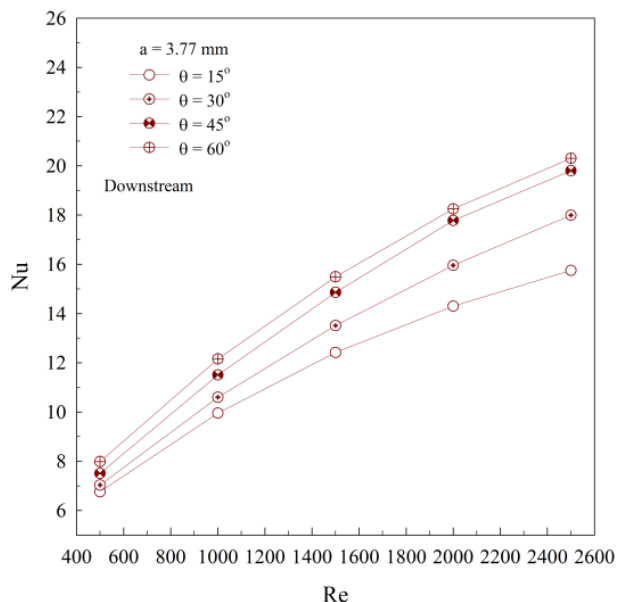

(a)

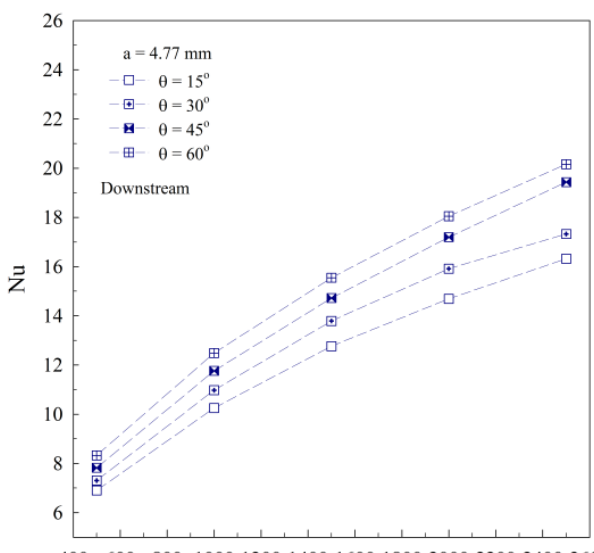

400600800100012001400160018002000220024002600

$\operatorname{Re}$

(b)

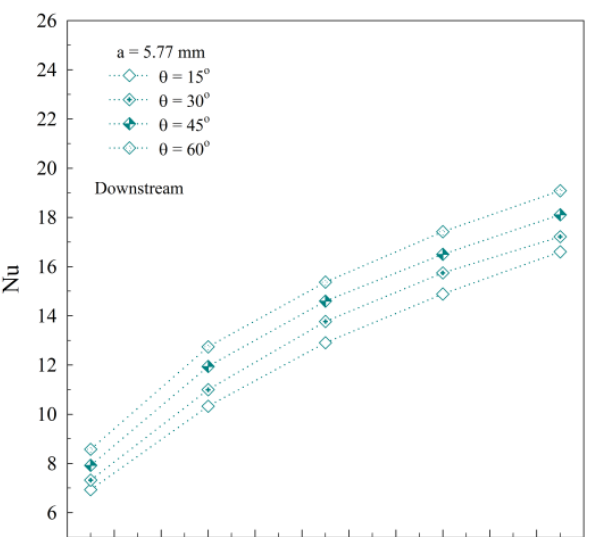

400600800100012001400160018002000220024002600

$\mathrm{Re}$

(c)

Fig. 15 The variations of Nusselt number with Reynolds number for (a) $a=3.77 \mathrm{~mm}$, (b) $a=4.77 \mathrm{~mm}$ and (c) $a=5.77 \mathrm{~mm}$.

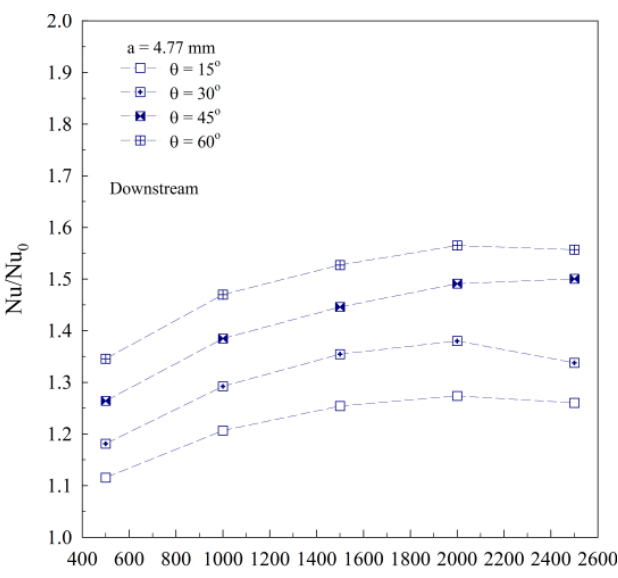

(a)

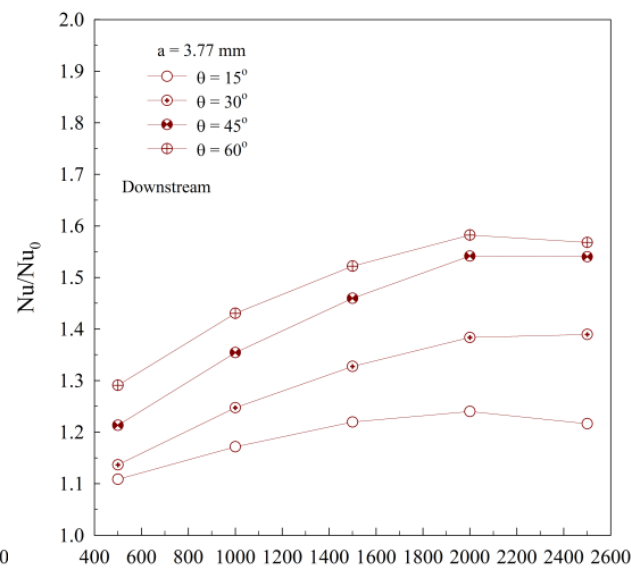

$\operatorname{Re}$

(b)

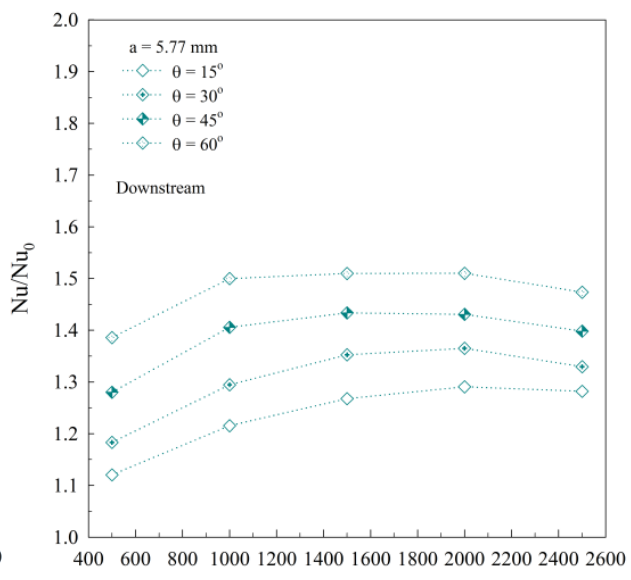

Re

(c)

Fig. 16 The variations of Nusselt number ratio with Reynolds number for (a) $a=3.77 \mathrm{~mm}$, (b) $a=4.77 \mathrm{~mm}$ and (c) $a=5.77 \mathrm{~mm}$.

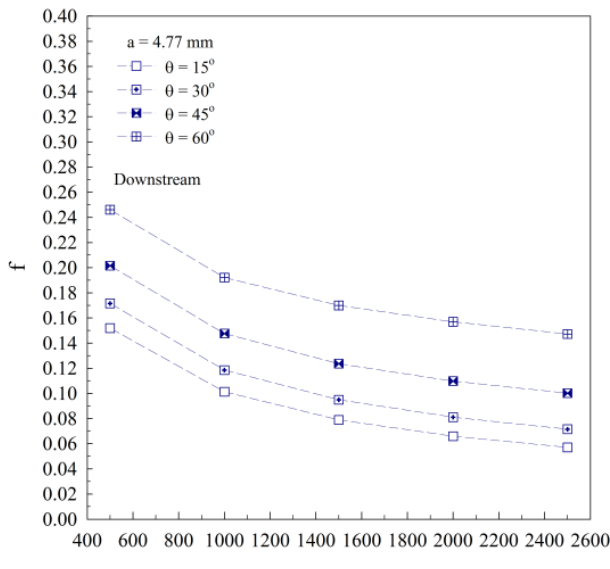

$\mathrm{Re}$

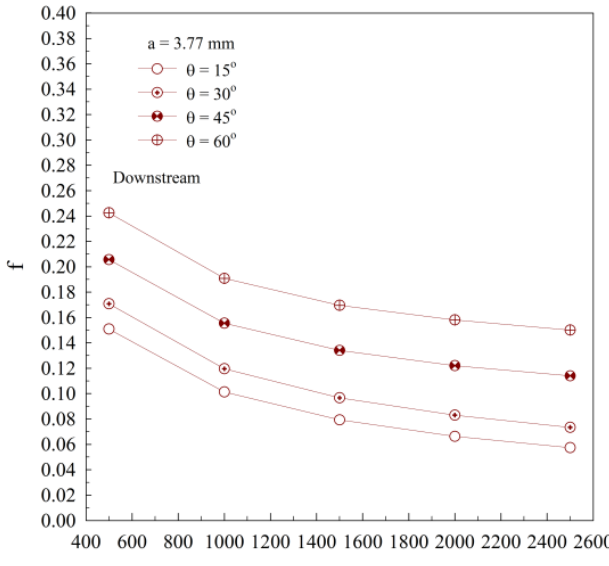

$\mathrm{Re}$

(b)

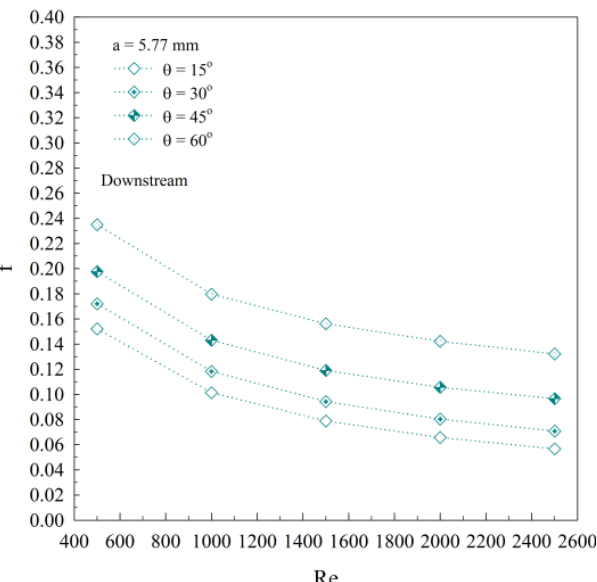

(c)

Fig. 17 The variations of friction factor with Reynolds number for (a) $a=3.77 \mathrm{~mm}$, (b) $a=4.77 \mathrm{~mm}$ and (c) $a=5.77 \mathrm{~mm}$. 


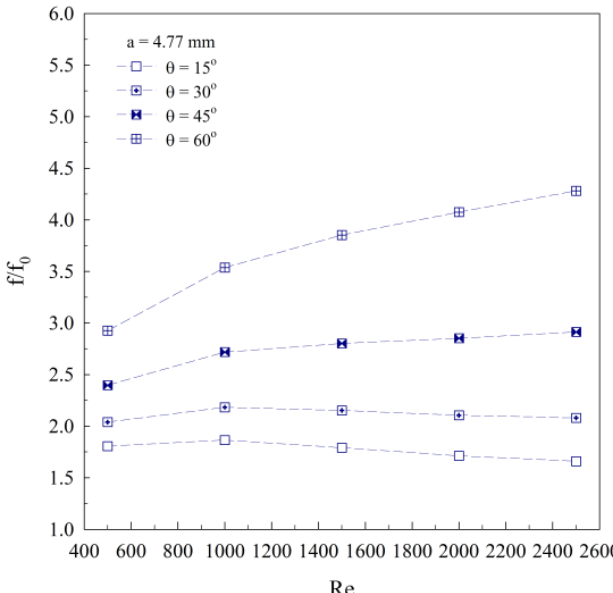

(a)

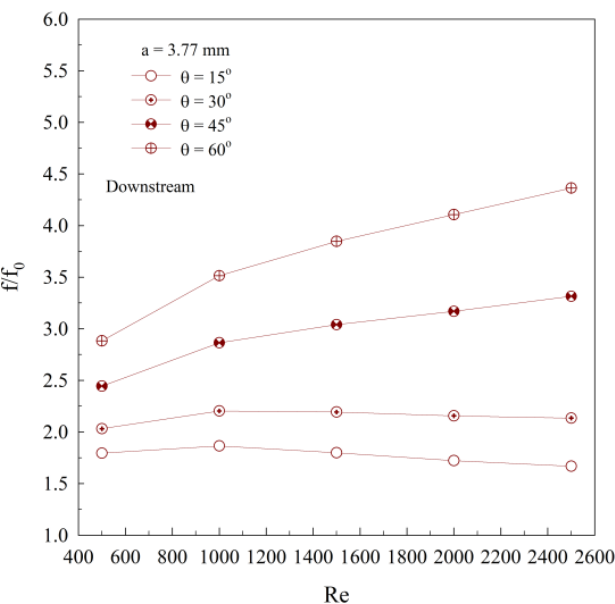

(b)

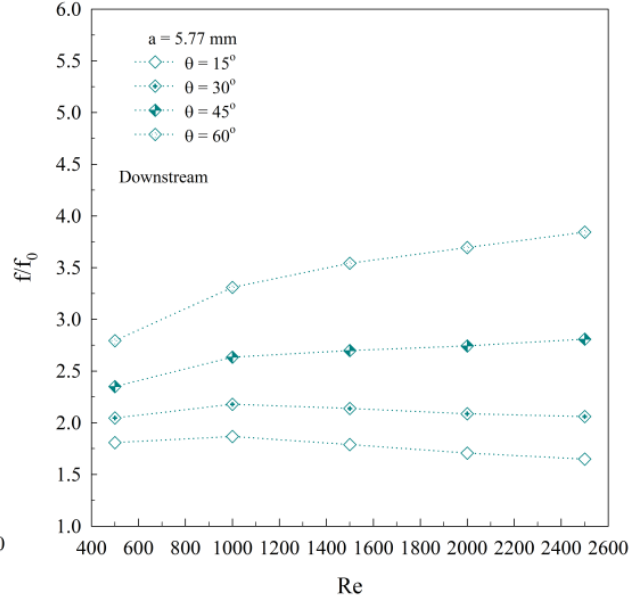

(c)

Fig. 18 The variations of friction factor ratio with Reynolds number for (a) $a=3.77 \mathrm{~mm}$, (b) $a=4.77 \mathrm{~mm}$ and (c) $a=5.77 \mathrm{~mm}$.

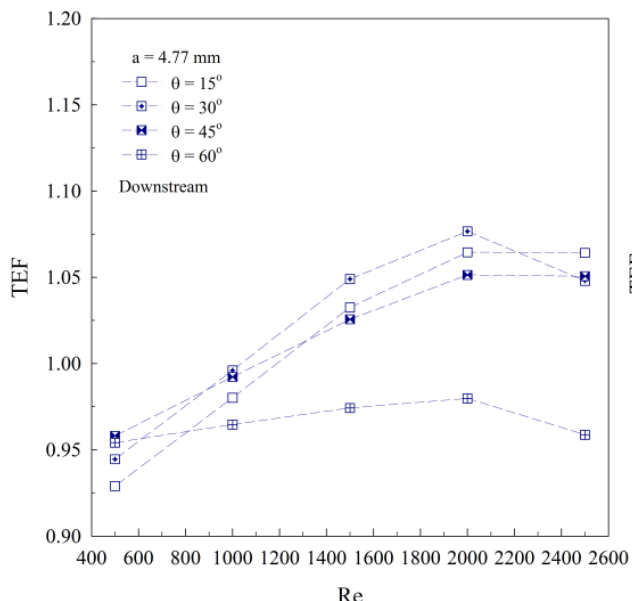

(a)

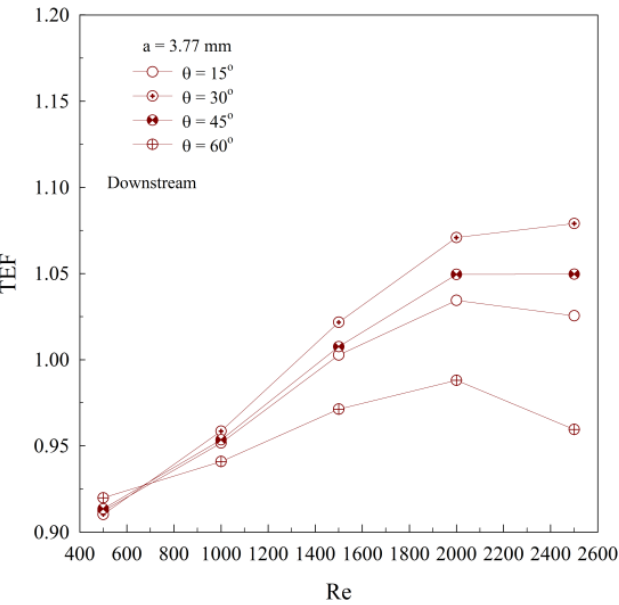

(b)

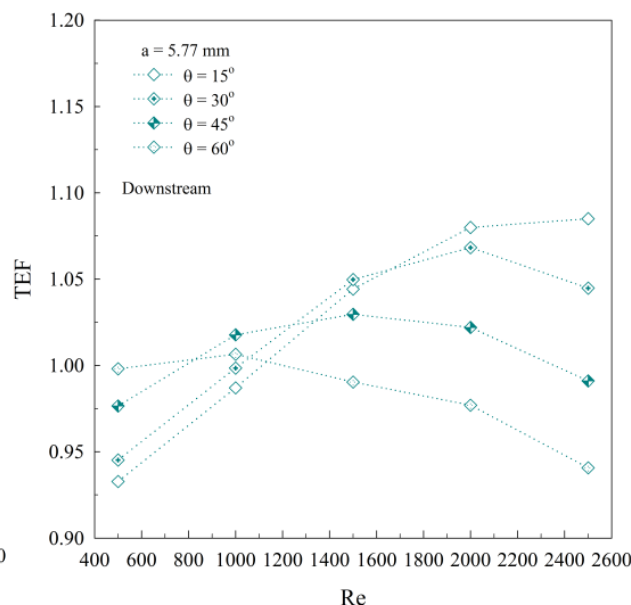

(c)

Fig. 19 The variations of thermal enhancement factor with Reynolds number for (a) $a=3.77 \mathrm{~mm}$, (b) $a=4.77 \mathrm{~mm}$ and (c) $a=5.77 \mathrm{~mm}$.

cases. The variations of $a$ value result in the slightly different on both the heat transfer rate and friction factor.

- The presence of the $D D W P$ s leads to the augment in the heat transfer rate and the friction factor over the smooth plain fin for all cases. The enhancement of the heat transfer rate is around $1.1-1.59$ times over the smooth plain tube while the pressure loss is higher than the smooth fin around $1.6-4.4$ times depended on the flow attack angle, the Reynolds number and the $a$ value.

- Owing to the computational domain of the fin-and-oval-tube heat exchanger similar to the rectangular channel, therefore, the thermal performance is considered in term of thermal enhancement factor, $T E F$. The $T E F$ varies in the range $0.91-1.09$ depended on the Reynolds number, the flow attack angle and $a$ value. The optimum $T E F$ is found 1.09 at $R e=2500, a=5.77 \mathrm{~mm}$ and $\theta=15^{\circ}$.

\section{ACKNOWLEDGEMENTS}

This research was funded by King Mongkut's University of Technology North Bangkok. Contract no. KMUTNB-GEN-58-52. The authors would like to thank Assoc. Prof. Dr.Pongjet Promvonge for the suggestions.

\section{NOMENCLATURE}

in transverse axis (mm)

$B \quad$ channel width (m)

$c \quad$ delta winglet chord length (m)

$c_{\mathrm{p}} \quad$ specific heat capacity $(\mathrm{kJ} / \mathrm{kg} \mathrm{K})$

$D_{\mathrm{h}} \quad$ hydraulic diameter

$D D W P$ downstream delta winglet pairs

$f \quad$ friction factor

$F_{\mathrm{p}} \quad$ fin pitch (m)

$F_{\mathrm{t}} \quad$ fin thickness (m)

$h \quad$ heat transfer coefficient $\left(\mathrm{W} / \mathrm{m}^{2} \mathrm{~K}\right)$

$H \quad$ channel height (m)

$k$ thermal conductivity (W/m K)

$L \quad$ flow length (m)

$L V G \quad$ longitudinal vortex generators

$n \quad$ tube row number

$\mathrm{Nu} \quad$ Nusselt number, $\left(h D_{\mathrm{h}}\right) / k$

$P \quad$ pressure $(\mathrm{Pa})$

$P_{1} \quad$ longitudinal tube pitch (m)

$P_{\mathrm{s}} \quad$ spanwise tube pitch (m)

$\Delta P \quad$ air-side pressure drop $(\mathrm{Pa})$

$R_{\mathrm{a}} \quad$ semi-major diameter

$R_{\mathrm{b}} \quad$ semi-minor diameter

Re Reynolds number, $R e=U_{\mathrm{c}} D_{\mathrm{h}} v$

$T$ temperature (K)

$T E F$ thermal enhancement factor, $T E F=\left(N u / N u_{0}\right)\left(f / f_{0}\right)^{-(1 / 3)}$

$T V G \quad$ transverse vortex generators 


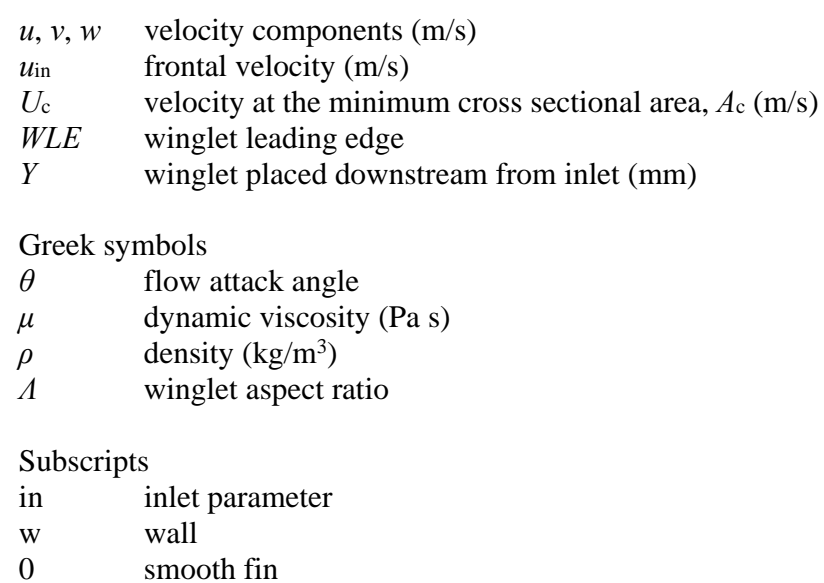

\section{REFERENCES}

Biswas, G., Torii, K., Fujii, D., Nishino, K., 1996, "Numerical and Experimental Determination of Flow Structure and Heat Transfer Effects of Longitudinal Vortices in a Channel Flow," International Journal of Heat and Mass Transfer, 39(16), 3441-3451. http://dx.doi.org/10.1016/0017-9310(95)00398-3

Chen, Y., Fiebig, M., Mitra, N.K., 1998, "Heat Transfer Enhancement of a Finned Oval Tube with Punched Longitudinal Vortex Generators In-line,” International Journal of Heat and Mass Transfer, 41, 41514166.

http://dx.doi.org/10.1016/S0017-9310(98)00130-6

Chen, Y., Fiebig, M., Mitra, N.K., 2000, "Heat Transfer Enhancement of Finned Oval Tube with Staggered Punched Longitudinal Vortex Generators,” International Journal of Heat and Mass Transfer, 43, 417-435.

http://dx.doi.org/10.1016/S0017-9310(99)00157-X

Chu, P., He, Y.L., Lei, Y.G., Tian, L.T., Li, R., 2009, “ThreeDimensional Numerical Study on Fin-and-oval-tube Heat Exchanger with Longitudinal Vortex Generators," Applied Thermal Engineering, 29, 859-876.

http://dx.doi.org/10.1016/j.applthermaleng.2008.04.021

Fiebig, M., 1995, "Embedded Vortices in Internal Flow: Heat Transfer and Pressure Loss Enhancement," International Journal of Heat and Fluid Flow, 16, 376-388.

http://dx.doi.org/10.1016/0142-727X(95)00043-P

Gentry, M.C., Jacobi, A.M., 2002, "Heat Transfer Enhancement by Delta-Wing-Generated Tip Vortices in Flat-plate and Developing Channel Flows," Journal of Heat Transfer, 124, 1158-1168. http://dx.doi.org/10.1115/1.1513578

Hiravennavar, S.R., Tulapurkara, E.G., Biswas, G., 2007, “A Note on the Flow and Heat Transfer Enhancement in a Channel with Built-in Winglet Pair," International Journal of Heat and Fluid Flow, 28, 299305.

http://dx.doi.org/10.1016/j.ijheatfluidflow.2006.03.030
Jacobi, A.M., Shah, R.K., 1995, "Heat Transfer Surface Enhancement Through the Use of Longitudinal Vortices: a Review of Recent Progress,” Experimental Thermal and Fluid Science, 11, 295-309. http://dx.doi.org/10.1016/0894-1777(95)00066-U

Lee, S.H., Ryou, H.S., Choi, Y.K., 1999, "Heat Transfer in a ThreeDimensional Turbulent Boundary Layer with Longitudinal Vortices,” International Journal of Heat and Mass Transfer, 42, 1521-1534. http://dx.doi.org/10.1016/S0017-9310(98)00290-7

Leu, J.S., Wu, Y.H., Jang, J.Y., 2004, "Heat Transfer and Fluid Flow Analysis in Plate-fin and Tube Heat Exchangers with a Pair of Block Shape Vortex Generators," International Journal of Heat and Mass Transfer, 47, 4327-4338.

http://dx.doi.org/10.1016/j.ijheatmasstransfer.2004.04.031

Liou, T.M., Chen, C.C., Tsai, T.W., 2000, "Heat Transfer and Fluid Flow in a Square Duct with 12 Different Shaped Vortex Generators," Journal of Heat Transfer, 122, 327- 335.

http://dx.doi.org/10.115/1.521487

O’Brien, J.E., Sohal, M.S., Wallstedt, P.C., 2004, “Local Heat Transfer and Pressure Drop for Finned-tube Heat Exchangers using Oval Tubes and Vortex Generators,” Journal of Heat Transfer, 126, 826-835. http://dx.doi.org/10.1115/1.1795239

Pesteei, S.M., Subbarao, P.M.V., Agarwal, R.S., 2005, "Experimental Study of the Effect of Winglet Location on Heat Transfer Enhancement and Pressure Drop in Fin-tube Heat Exchangers," Applied Thermal Engineering, 25, 1684-1696.

http://dx.doi.org/10.1016/j.applthermaleng.2004.10.013

Sommers, A.D., Jacobi, A.M., 2005, “Air-side Heat Transfer Enhancement of a Refrigerator Evaporator using Vortex Generation,” International Journal of Refrigeration, 28, 1006-1017. http://dx.doi.org/10.1016/j.ijrefrig.2005.04.003

Sriromreun, P., Thianpong, C., Promvonge, P., 2012, “Experimental and Numerical Study on Heat Transfer Enhancement in a Channel with Z-shaped Baffles," International Communications in Heat and Mass Transfer, 39, 945-952.

http://dx.doi.org/10.1016/j.icheatmasstransfer.2012.05.016

Tiwari, S., Maurya, D., Biswas, G., Eswaran, V., 2003, “Heat Transfer Enhancement in Cross-flow Heat Exchangers using Oval Tubes and Multiple Delta Winglets," International Journal of Heat and Mass Transfer, 46, 2841-2856. http://dx.doi.org/10.1016/S0017-9310(03)00047-4

Torii, K., Kwak, K.M., Nishino, K., 2002, “Heat Transfer Enhancement Accompanying Pressure-loss Reduction with Winglet-type Vortex Generators for Fin-tube Heat Exchangers,” International Journal of Heat and Mass Transfer, 45, 3795-3801. http://dx.doi.org/10.1016/S0017-9310(02)00080-7

Zhu, J.X., Fiebig, M., Mitra, N.K., 1995, "Numerical Investigation of Turbulent Flows and Heat Transfer in a Rib-roughened Channel with Longitudinal Vortex Generators, “ International Journal of Heat and Mass Transfer, 38 (3), 495-501. http://dx.doi.org/10.1016/0017-9310(94)00177-W 